\title{
A partial skeleton of a new species of Tynskya Mayr, 2000 (Aves, Messelasturidae) from the London Clay highlights the osteological distinctness of a poorly known early Eocene "owl/parrot mosaic"
}

\author{
Gerald Mayr ${ }^{1}$ (D)
}

Received: 27 August 2020 / Accepted: 5 December 2020 / Published online: 1 March 2021

(c) The Author(s) 2021

\begin{abstract}
Tynskya eocaena is an early Eocene bird with a raptor-like skull and semi-zygodactyl feet, whose description is based on a skeleton from the North American Green River Formation. In the present study, three-dimensionally preserved bones of a new species of Tynskya, T. waltonensis, are reported from the London Clay of Walton-on-the-Naze (Essex, UK). The fossils belong to a single individual and provide new insights into the skeletal morphology of messelasturids. In particular, they reveal unusual vertebral specializations, with the cervical vertebrae having concave rather than saddle-shaped caudal articulation facets and the caudalmost thoracic vertebra being platycoelous (flat articular surfaces). The very deep mandible and a derived morphology of the ungual phalanges support a sister group relationship between Tynskya and the taxon Messelastur (Messelasturidae). Phylogenetic analyses of an emended data matrix did not conclusively resolve the higher-level affinities of messelasturids and the closely related halcyornithids, with both taxa sharing derived characters with only distantly related extant taxa (Accipitriformes, Strigiformes, Falconiformes, and Psittaciformes). An analysis that was constrained to a molecular scaffold, however, recovered messelasturids as the sister taxon of a clade including psittaciform and passeriform birds. The derived morphologies of the mandible and cervical vertebrae suggest specialized feeding adaptations of Tynskya, and messelasturids may have exploited a feeding niche, which is no longer available to extant birds.
\end{abstract}

Keywords Fossil birds $\cdot$ Tynskya waltonensis sp. nov. $\cdot$ Messelasturidae $\cdot$ Walton-on-the-naze $\cdot$ Ypresian

\section{Introduction}

Early Cenozoic fossils often exhibit mosaic character distributions, which impede a straightforward phylogenetic assignment. Such is particularly true for the Messelasturidae and Halcyornithidae, which occur in the early Eocene of Europe and North America and combine derived characteristics of owls (Strigiformes), diurnal birds of prey (Accipitriformes and Falconiformes), and parrots (Psittaciformes).

The first formally described messelasturid fossils are two skulls of Messelastur gratulator from the early Eocene of Messel in Germany (Peters 1994), which were originally

Handling Editor: Ursula Göhlich.

Gerald Mayr

Gerald.Mayr@senckenberg.de

1 Senckenberg Research Institute and Natural History Museum Frankfurt, Ornithological Section, Senckenberganlage 25, 60325 Frankfurt am Main, Germany considered to be from a hawk-like diurnal bird of prey (Accipitridae). Subsequently, two skeletons from Messel were assigned to Messelastur, which revealed the distinctive skeletal morphology of this taxon (Mayr 2005, 2011). These new fossils indicated close affinities between $M$. gratulator and Tynskya eocaena, a species from the early Eocene North American Green River Formation (Mayr 2000).

T. eocaena was initially considered to be of uncertain phylogenetic affinities, but the species was compared with owls and diurnal birds of prey (Mayr 2000). The first skeleton of M. gratulator likewise prompted comparisons with owls and diurnal birds of prey, and a phylogenetic analysis supported a sister group relationship between Messelasturidae and Strigiformes, with the clade including both taxa being nested amongst diurnal birds of prey (Mayr 2005). Mayr $(2000,2005,2011)$ emphasized the mosaic nature of the skeletal morphology of Tynskya, which combines several "raptor-like" traits, such as a short beak and long supraorbital processes, with a "parrot-like" tarsometatarsus morphology indicating at least semi-zygodactyl feet (fourth toe partly 
or fully reversed). However, well-resolved and congruent molecular phylogenies now provide a robust framework for the placement of psittaciform, falconiform, accipitriform, and strigiform birds, which are only distantly related (Ericson et al. 2006; Hackett et al. 2008; Jarvis et al. 2014; Prum et al. 2015; Kuhl et al. 2021). According to these phylogenies, the character mosaic displayed by T. eocaena is the result of a strongly homoplastic evolution.

Mayr $(2000,2005)$ noted that messelasturids show similarities to the Halcyornithidae, another taxon of Eocene birds with zygodactyl feet, which were then considered to be stem group representative of the Psittaciformes (Mayr 2002, 2009). Improved knowledge of the osteology of Messelastur subsequently strengthened affinities to the Halcyornithidae, and messelasturids were also tentatively considered to be stem-group representatives of the Psittaciformes (Mayr 2011). Like messelasturids, halcyornithids were likened to owls (Hoch 1988) and diurnal birds of prey (Mayr 1998), before they were hypothesized to be stem-group representatives of the Psittaciformes (Mayr 2002, 2009, 2015; Ksepka et al. 2011). Still, the affinities of messelasturids and halcyornithids are not well resolved. Even though both taxa were obtained in a clade by Mayr et al. (2013), another analysis failed to recover close affinities and did not support psittaciform affinities of either halcyornithids or messelasturids (Mayr 2015). In the most recent analysis of Ksepka et al. (2019), halcyornithids resulted as the sister group of a clade formed by Psittaciformes and Passeriformes; this study did not include messelasturids.

The holotype of T. eocaena (Fig. 1a, b) and all specimens of $M$. gratulator are articulated (partial) skeletons on slabs and only a limited amount of osteological details can therefore be recognized in these fossils. In the original description of T. eocaena, it was already noted that well-preserved messelasturid fossils were discovered by amateur collectors in the early Eocene London Clay of Walton-on-the-Naze (Essex, UK; see also Mayr 2009), but at this time all of these specimens were in private collections and therefore not available for a formal description. Recently, however, Senckenberg Research Institute acquired a partial skeleton of a London Clay messelasturid from the collection of the late Paul Bergdahl (Kirby-le-Soken, UK), which is described in the present study. This fossil includes several skeletal elements, whose morphology cannot be assessed in the holotype of T. eocaena, and thereby adds to an improved knowledge of the osteology of the taxon Tynskya and messelaturids in general.

In addition, the counter slab of the holotype of Tynskya eocaena is examined, which was not available at the time the species was first described and has shortly thereafter been acquired. Although many parts of this specimen are fabricated, it provides new data on some skeletal elements that are absent or poorly preserved in the main slab of the $T$. eocaena holotype.

\section{Material and methods}

The fossils are deposited in the Staatliche Naturwissenschaftliche Sammlungen Bayerns-Bayerische Staatssammlung für Paläontologie und Geologie, Munich, Germany (SNSB-BSPG), the Geiseltalsammlung, Martin-Luther Universität of Halle-Wittenberg, Germany (GMH), H.N.B. Garhwal University, Department of Geology, Uttarakhand, India (GU/RSR/VAS), and the Senckenberg Research Institute, Frankfurt, Germany (SMF).

To assess the affinities of Tynskya, a phylogenetic analysis of 77 morphological characters was performed based on an emended character matrix of Mayr (2015) (see appendices for character descriptions and matrix). In a second analysis, 20 "dummy" characters were added to constrain the topology of the extant taxa according to the results of comprehensive recent molecular analyses, which congruently recover a clade (Falconiformes + (Psittaciformes + Passeriformes)) (Ericson et al. 2006; Hackett et al. 2008; Jarvis et al. 2014; Prum et. al. 2015; Kuhl et al. 2021). Accordingly, in this second analysis, 10 "dummy" characters were scored as " 1 " for Psittacidae and Passeriformes and 10 further characters were scored as "1" for Falconidae, Psittacidae and Passeriformes; these characters were scored as " 0 " for all other extant taxa and as unknown (“?”) for all fossil taxa.

The analyses were run with the heuristic search modus of NONA 2.0 (Goloboff 1993) through the WINCLADA 1.00 .08 interface (Nixon 2002), using the commands hold 10,000 , mult*1000, hold/10, and max*. Bootstrap support values were calculated with 1000 replicates, ten searches holding ten trees per replicate, and TBR branch swapping without $\max ^{*}$. Outgroup comparisons were made with the anseriform Anhimidae. Tree length (L), consistency index (CI), and retention index (RI) were calculated. Two characters (58 and 66 in the appendix) were coded as additive.

\section{Systematic Paleontology}

Aves Linnaeus, 1758

Messelasturidae Mayr, 2005

Genus Tynskya Mayr, 2000

Taxonomic remarks. Even though the new fossil is fragmentary and lacks major limb bones, it shows a characteristic derived trait of the Messelasturidae in that the mandibular 

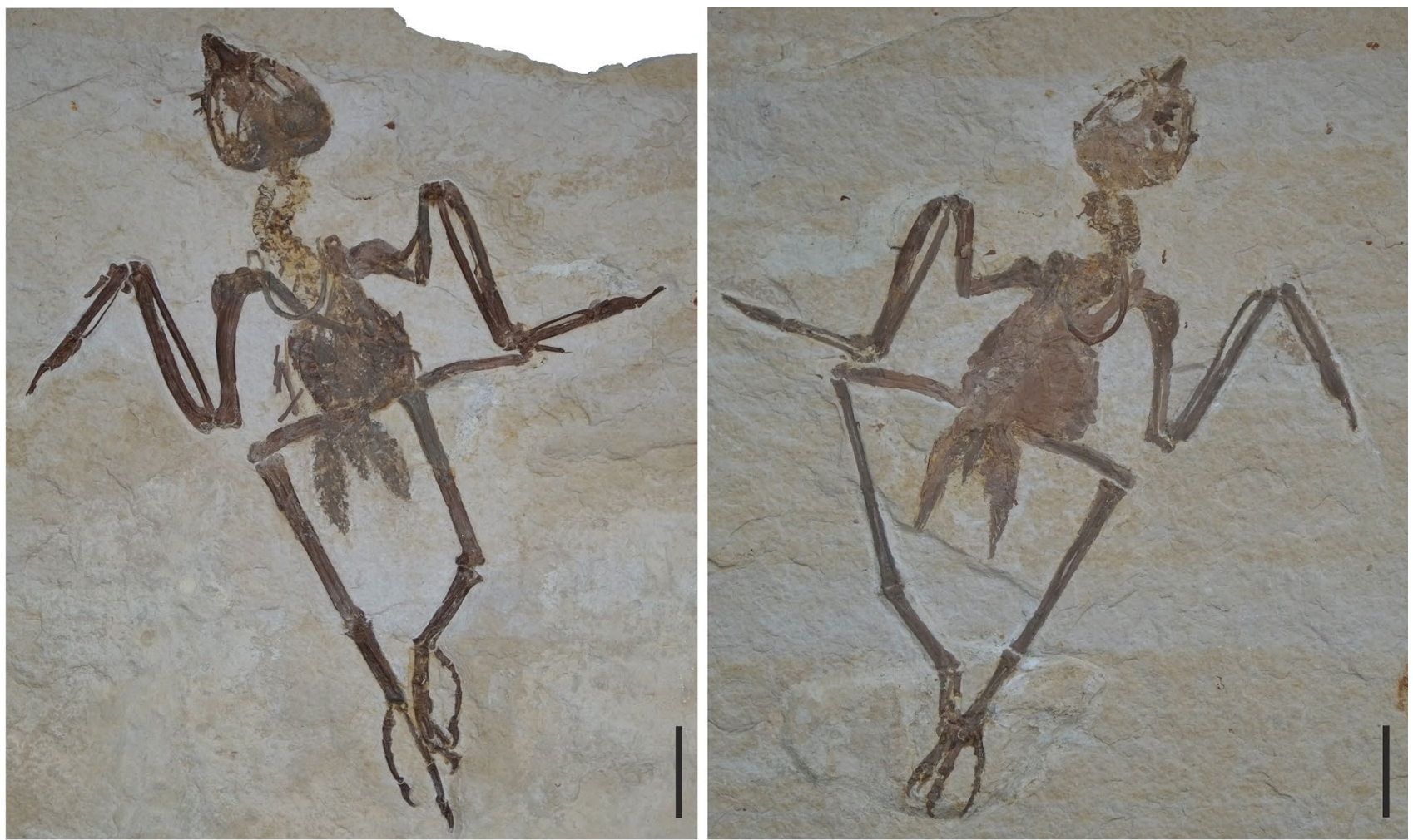

a

b
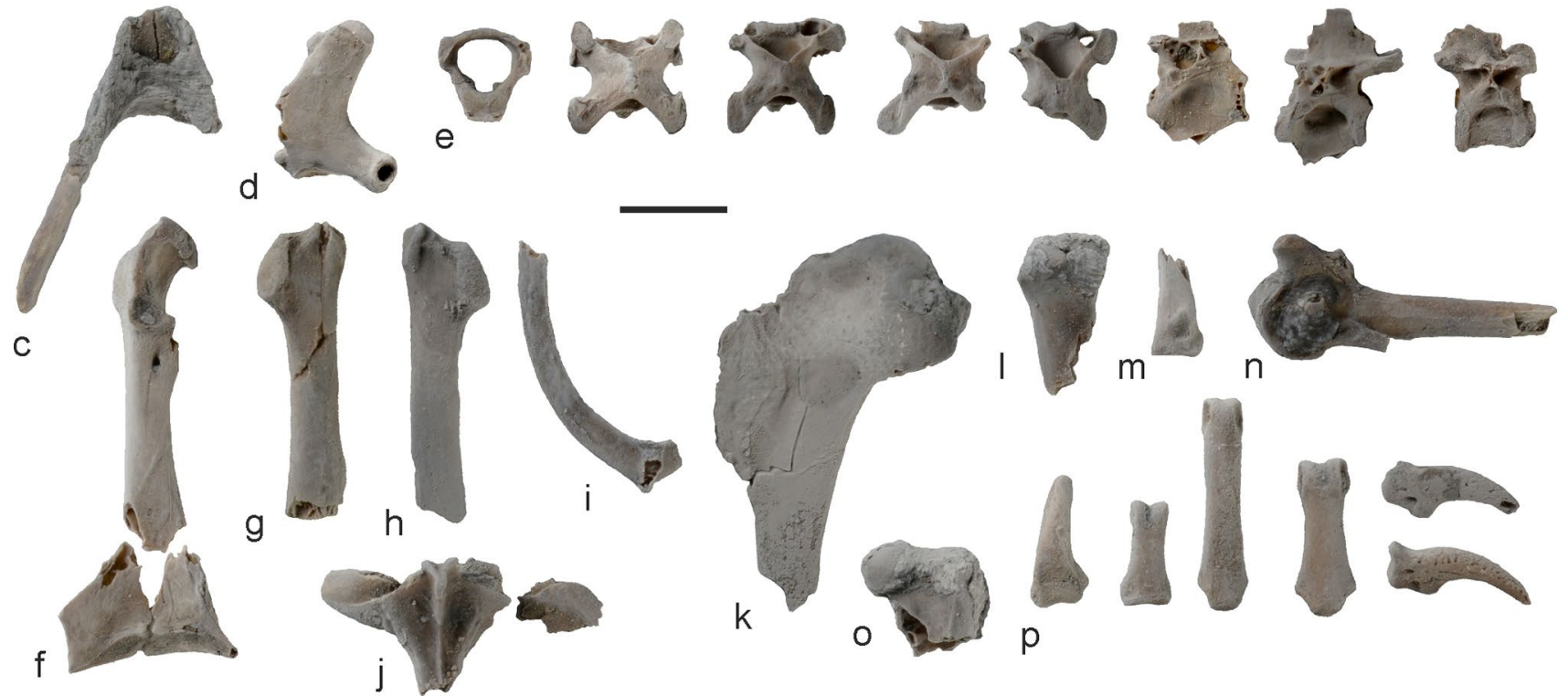

Fig. 1 a, b Main slab (a) and counter slab (b) of the Tynskya eocaena holotype from the North American Green River Formation (SNSBBSPG 1997 I 6); note that most limb bones of the counter slab have been fabricated by the preparator of the fossil. c-p Partial skeleton of Tynskya waltonensis sp. nov. from the early Eocene London Clay of Walton-on-the-Naze, Essex, UK (SMF Av 652); all bones are from a single individual, unidentifiable or uninformative fragments pre- served in the specimen are not shown; $\mathbf{c}$ mandible, $\mathbf{d}$ left quadrate, $\mathbf{e}$ vertebrae, $\mathbf{f}$ left coracoid, $\mathbf{g}, \mathbf{h}$ left and right scapula, $\mathbf{i}$ furcula, $\mathbf{j}$ fragment of sternum, $\mathbf{k}$ right humerus, $\mathbf{l}$ distal end of left ulna, $\mathbf{m}$ proximal end of right radius, $\mathbf{n}$ partial left carpometacarpus, $\mathbf{o}$ proximal end of left femur, $\mathbf{p}$ left os metatarsale I and pedal phalanges. Scale bars equal $20 \mathrm{~mm}$ for $\mathbf{a}$ and $\mathbf{b}$ and $5 \mathrm{~mm}$ for $\mathbf{c}-\mathbf{p}$ 
rami are unusually deep. An assignment to the Messelasturidae is further supported by the shape of the raptor-like ungual pedal phalanges, in which the neurovascular sulci are laterally closed. In size and overall morphology of the preserved bones, the London Clay fossil closely resembles the holotype of Tynskya eocaena, whereas Messelastur gratulator is larger than T. eocaena (humerus length 43.0-47.6 mm versus $36.6 \mathrm{~mm}$; Mayr 2000, 2011) and has a proportionally shorter and stouter tarsometatarsus (Mayr 2011). The tarsometatarsus is not preserved in SMF Av 652, but a Tynskyalike tarsometatarsus of a messelasturid from Walton-on-theNaze was figured by Mayr (2000: fig. 6). The specimen is likely to be from the same species as the fossil described in the present study and corroborates an assignment to the taxon Tynskya. An assignment of the ca. 55 million years old London Clay fossil to the taxon Tynsyka is also in agreement with its closer temporal proximity to the 52 myo strata of the Green River Formation (the type locality of T. eocaena; Grande 2013) than to the 48 myo Messel oilshale (the type locality of $M$. gratulator).

\section{Tynskya waltonensis sp. nov.}

Figures 1c-p, 2a-1; 3a-d; 4a-d, 1, o-z, aa-kk, ll-nn; 5a-c, e-n; 6a, b, d-f, i, j; 7c-u.

Holotype. SMF Av 652: partial skeleton comprising the left quadrate, a partial mandible, at least nine vertebrae, a cranial fragment of the sternum, a partial furcula, a partial left coracoid, the cranial ends of both scapulae, the proximal end of the right humerus, the distal end of the left ulna, the proximal end of the right radius, the proximal end of the left carpometacarpus, the proximal end of the left femur, five pedal phalanges, and the left os metatarsale I (Fig. 1c); the fossil was found in 1986 by Paul Bergdahl (original collector's number BC 8611).

Diagnosis. The new species differs from Tynskya eocaena in the shape of the processus acrocoracoideus of the coracoid, which is proportionally narrower, with the facies articularis clavicularis forming a better defined medial hook; the scapus of the furcula is furthermore not widened in its omal section and the tip of the processus extensorius of the carpometacarpus is somewhat more proximally directed. Messelastur gratulator is larger than both T. eocaena and T. waltonensis (see taxonomic remarks above).

Type locality and horizon. Walton-on-the-Naze, Essex, United Kingdom; Walton Member of the London Clay Formation (previously Division A2; Jolley 1996; Aldiss 2012), early Eocene (early Ypresian; 54.6-55 million years ago; Collinson et al. 2016).
Measurements (in mm). Quadrate, maximum dorsoventral depth (tip of processus oticus to tip of processus mandibularis), 8.4; humerus, maximum width of proximal end, 11.8; coracoid, reconstructed length, 21-22; os metatarsale I, 6.1. Pedal phalanges: II1, 4.9; III2, 7.6; III3, 10.1 .

Etymology. The species epithet refers to the type locality Walton-on-the-Naze.

Description and comparisons. The left quadrate lacks the processus orbitalis, but is otherwise complete (Fig. 2a-1). The bone is unknown for T. eocaena, and in fossils of Messelastur gratulator only small portions of it are visible (Mayr 2005). In SMF Av 652, the caudal surface of the processus oticus lacks pneumatic foramina but exhibits a distinct fossa caudalis. This fossa is also present in the Accipitridae, but it is absent in the Psittacidae, Falconidae, and Strigiformes. The capitulum oticum is smaller than the capitulum squamosum, and the incisura intercapitularis is shallow. The foramen pneumaticum mediale (sensu Elzanowski et al. 2001) is situated in a fossa, which is delimited by fine ridges along its margins; in the dorsal portion of this fossa there is distinct pit (Fig. 2b, h). The long condylus lateralis bears a deep and circular cotyla quadratojugalis. As in the Strigiformes, but unlike in the Accipitridae and Falconidae, the main (transversal) axis of the processus mandibularis is oriented subparallel to the main axis of the processus oticus. A distinctive feature of the bone is the fact that the lateral articular surface of the low condylus medialis exhibits a markedly concave articulation facet for the mandible (Fig. 2c, i), which amongst extant Telluraves, the clade including most arboreal landbirds, is only found in the Cathartidae (New World vultures) and some Falconidae (Mayr and Clarke 2003: character 37). The condylus caudalis forms a small, caudally projecting lip (Fig. 2e, k). The condylus pterygoideus is small but well-defined (in strigiform birds, the condyle is reduced). In overall shape, the quadrate of Tynskya resembles that of Elanus leucurus (Accipitridae; Fig. $2 \mathrm{~m}-\mathrm{o}$ ), in which, however, the tip of the condylus lateralis forms a dorsal lip that reaches beyond the cotyla quadratojugalis, and in which the condylus medialis lacks a concave lateral articular surface. The quadrate of the Falconidae (Fig. $2 \mathrm{v}-\mathrm{x}$ ) is likewise similar, but differs from Tynskya in that the caudal portion of the processus mandibularis forms a marked shelf; unlike in the Accipitridae, the condylus medialis of the Falconidae exhibits a concave lateral articular surface, which is, however, less pronounced than in the fossil. Amongst others, the quadrate of Tynskya is distinguished from that of crown group Strigiformes (Fig. $2 p-r$ ) in the much shorter capitulum oticum, which forms a long process in extant owls; the condylus medialis of crown group Strigiformes furthermore lacks a concave lateral articular surface and the 

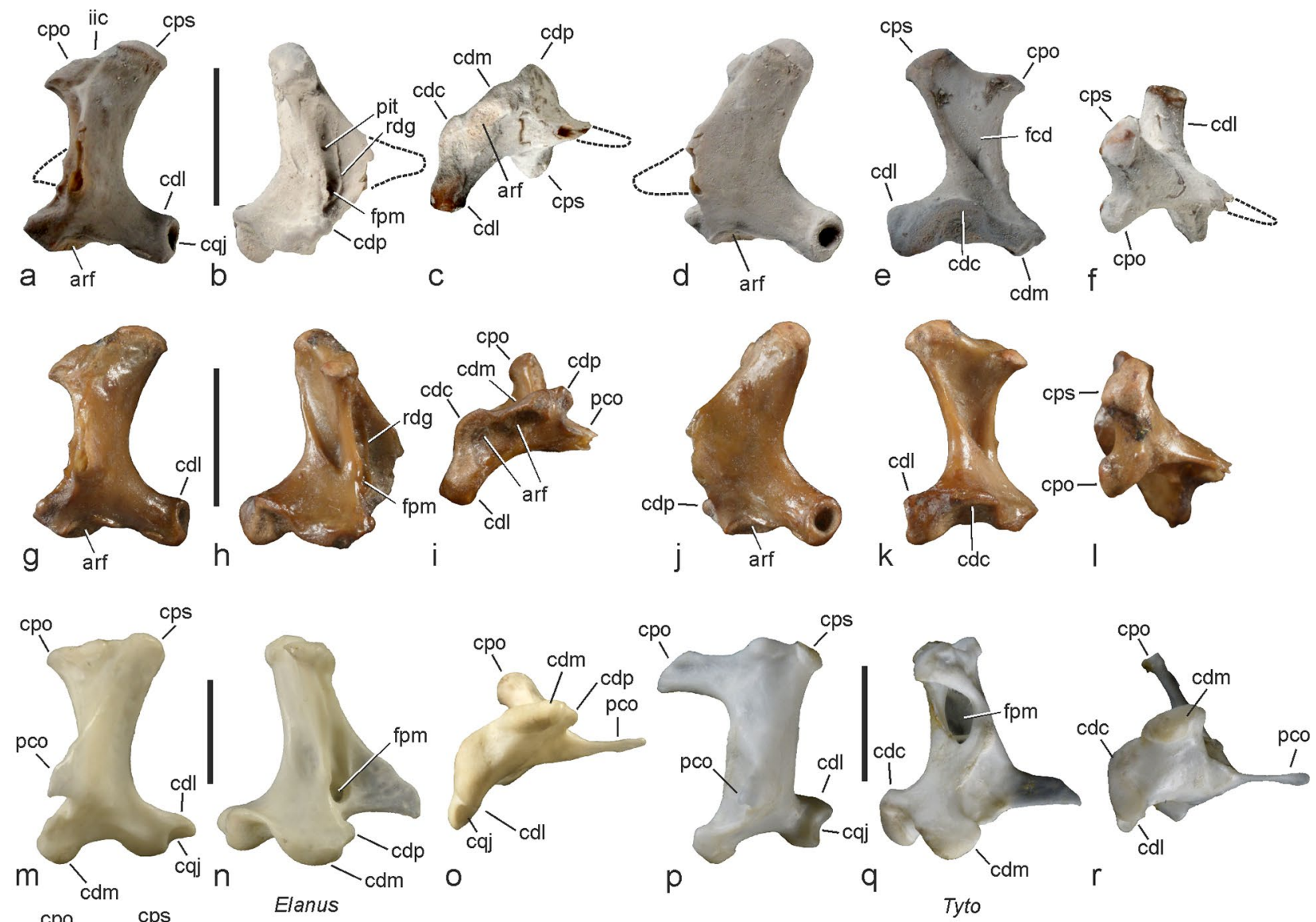

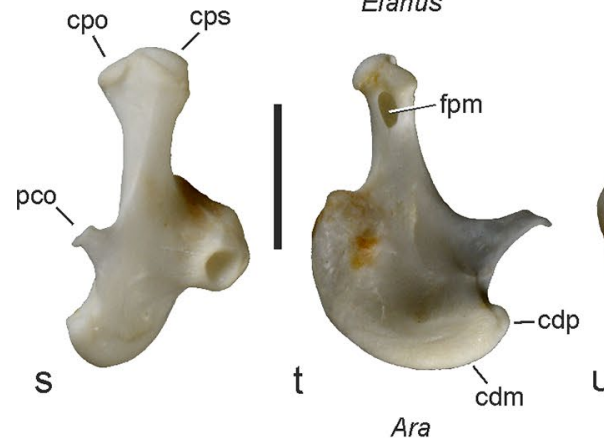

Ara

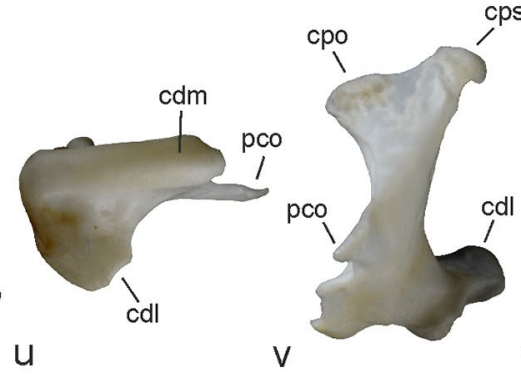

V

Fig. 2 Tynskya waltonensis sp. nov. from the early Eocene London Clay of Walton-on-the-Naze (SMF Av 652), $\mathbf{a}-\mathbf{l}$ left quadrate in different views, compared to $\mathbf{m}-\mathbf{x}$ the quadrates of selected extant taxa. $\mathbf{a}-\mathbf{l}$ fossil quadrate in rostral $(\mathbf{a}, \mathbf{g})$, medial $(\mathbf{b}, \mathbf{h})$, ventral $(\mathbf{c}, \mathbf{i})$, lateral $(\mathbf{d}, \mathbf{j})$, caudal $(\mathbf{e}, \mathbf{k})$, and dorsal $(\mathbf{f}, \mathbf{l})$ view; in $\mathbf{a}-\mathbf{f}$ the bone is coated with ammonium chloride, $\mathbf{g}-\mathbf{l}$ show views of the uncoated specimen, which in some cases are slightly differently oriented (the seemingly different width of the processus mandibularis in $\mathbf{e}$ and $\mathbf{k}$, for example, is due to a slightly different orientation of the bone). m-o Left quadrate of Elanus leucurus (Accipitriformes, Accipitridae) in rostral (m), medial (n), and ventral (o) view. p-r Left quadrate of Tyto alba (Strigiformes, Tytonidae) in rostral (p), medial (q), and ventral (r) view. s-u Left quadrate of Ara nobilis (Psittaciformes,

foramen pneumaticum mediale is much larger and situated further dorsally. Meaningful comparisons with the quadrate of crown group Psittaciformes are impeded by the highly
Psittacidae) in rostral (s), medial (t), and ventral (u) view. v-x Left quadrate of Falco tinnunculus (Falconiformes, Falconidae) in rostral (v), medial (w), and ventral (x) view. The dotted lines in $\mathbf{a}-\mathbf{d}$ and $\mathbf{f}$ indicate the (hypothetical) shape of the broken processus orbitalis. arf concave lateral articulation facet of condylus medialis, $c d c$ condylus caudalis, $c d l$ condylus lateralis, $c d m$ condylus medialis, $c d p$ condylus pterygoideus, cpo capitulum oticum, $c p s$ capitulum squamosum, $c q j$ cotyla quadratojugalis, $f c d$ fossa caudalis, $f p m$ foramen pneumaticum mediale, iic incisura intercapitularis, pco processus orbitalis, pit pit in fossa encompassing foramen pneumaticum mediale, $r d g$ ridges delimiting fossa that encompasses foramen pneumaticum mediale. Scale bars equal $5 \mathrm{~mm}$

derived quadrate morphology of extant parrots (Fig. 2s-u), which, among others, have a much narrower processus oticus, a strongly reduced processus orbitalis, and a reduced 


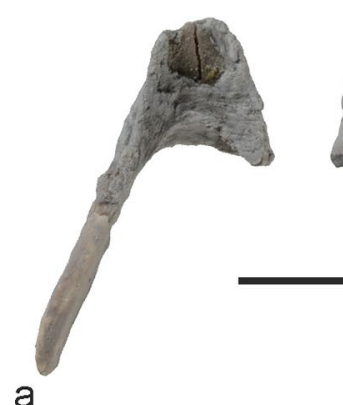

a

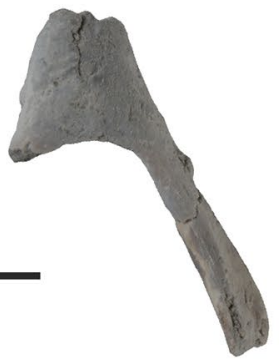

b
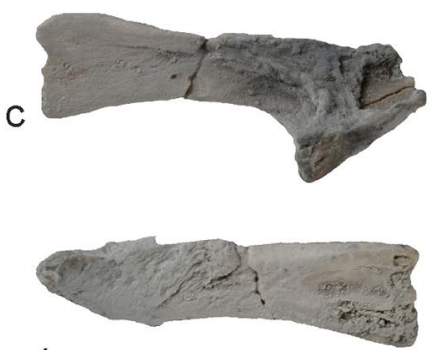

d

Fig. 3 a-d Tynskya waltonensis sp. nov. from the early Eocene London Clay of Walton-on-the-Naze (SMF Av 652), mandible in dorsal (a), ventral (b), right dorsolateral (c), and left lateral (d) view. e, f Partial mandible from the middle Eocene of the German locality Geiseltal (GMH XL-1-109), which was tentatively referred to the

condylus caudalis; the condylus medialis of parrots lacks a concave lateral articular surface.

The fossil from Walton-on-the-Naze for the first time allows an assessment of the shape of the mandible of Tynskya, of which a large portion is preserved in the fossil (Fig. 3a-d; in the holotype of T. eocaena only small mandibular fragments are exposed and these do not allow a meaningful description). As in Messelastur (Fig. 3g), the mandibular rami are very deep, with their depth increasing in a caudal direction. The mandibular symphysis, whose tip is broken, is short and broad. Parts of it are covered with a very hard pyrite layer, which obscures surface details, but it can still be discerned that the symphysis is notably deep with an only weakly concave dorsal surface. The mandible of the Halcyornithidae (Mayr 1998, Ksepka et al. 2011 and Fig. 3e, f) also has deep mandibular rami, which taper, however, towards the tip of the mandible; in addition, the mandibular symphysis is proportionally longer and narrower in the Halcyornithidae.

No meaningful details of the vertebral column can be discerned in the holotype of T. eocaena. In the fossil from Walton-on-the-Naze at least nine praesacral vertebrae or fragments thereof are preserved, including the atlas as well as four other cervical and three thoracic vertebrae (Fig. 4). The atlas (Fig. 4a, b) exhibits a dorsally open incisura fossae and weakly prominent processus articulares caudales; the processus ventralis is broken and missing; overall, the bone
Halcyornithidae by Mayr (2020) in dorsal (e) and left lateral (f) view. g Skull of Messelastur gratulator from the latest early/earliest middle Eocene of Messel in Germany (holotype, SMF-ME 2024); note the deep mandibular rami. All specimens were coated with ammonium chloride. Scale bars equal $5 \mathrm{~mm}$

resembles the atlas of strigiform, psittaciform, and falconiform birds.

The most notable characteristic of the other cervical vertebrae concerns the shape of the caudal articulation facet (facies articularis caudalis), which is mediolaterally narrow and deeply concave (Fig. 4d, 1, q, u, x); the ventral portion of the articulation facet forms a lip-like process. This morphology does not occur in any extant avian taxon, in which the cervical vertebrae are heterocoelous and have saddleshaped caudal articulation facets (Fig. 4m, n, r); in most extant birds the facies articulares caudales are furthermore much wider in mediolateral than in dorsoventral direction, whereas they are as wide (mediolaterally) as they are deep (dorsoventrally) in the fossil (Fig. 4l-n). The facies articulares craniales of the cervical vertebrae of SMF Av 652 have the usual width, but have a more convex articulation facet than in most extant birds (compare Figs. 5h, o).

The fourth cervical vertebra (Fig. $4 \mathrm{c}-\mathrm{g}$ ) bears a distinct, spine-like processus spinosus, which is also found in extant Strigiformes and Accipitridae, whereas this process is lower or more elongate and ridge-like in many other extant representatives of Telluraves. The zygapophysis cranialis forms a caudally directed process, which, together with a very small cranial process at the base of the zygapophysis caudalis, delimits a marked lateral concavity (concavitas lateralis; Fig. 4c). Unlike in most extant Telluraves, the fourth cervical also exhibits a long processus ventralis. 


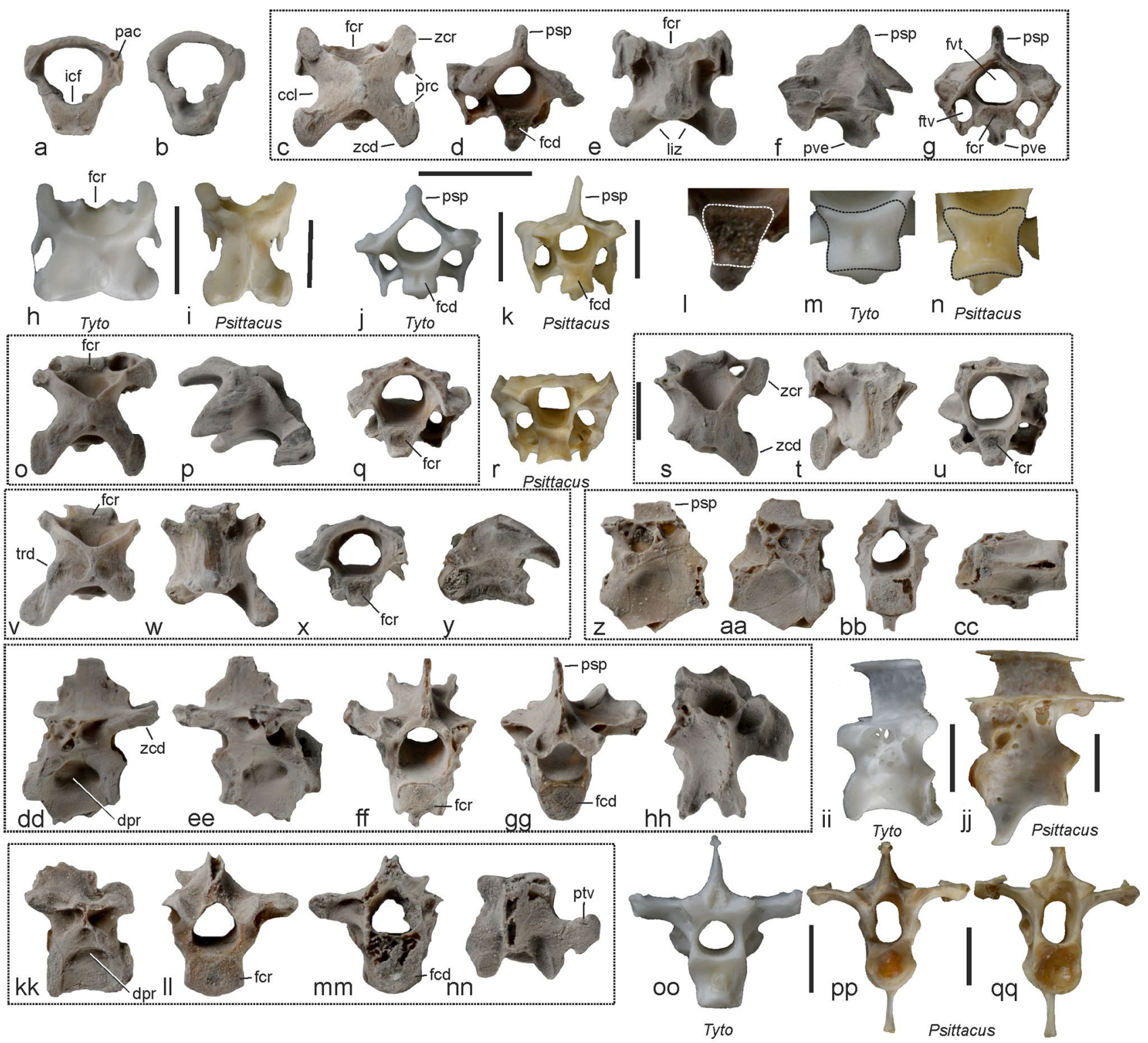

Fig. 4 Tynskya waltonensis sp. nov. from the early Eocene London Clay of Walton-on-the-Naze (SMF Av 652), vertebrae. a, b Atlas in caudal (a) and cranial (b) view. c-g Fourth cervical vertebra in dorsal (c), caudal (d), ventral (e), left lateral (f) and cranial (g) view. h-k Fourth cervical vertebra of $\mathbf{h}, \mathbf{j}$ Tyto alba (Strigiformes, Tytonidae) and $\mathbf{i}$, $\mathbf{k}$ Psittacus erithacus (Psittaciformes, Psittacidae) in dorsal $(\mathbf{h}, \mathbf{i})$ and caudal $(\mathbf{j}, \mathbf{k})$ view. $\mathbf{l}-\mathbf{n}$ Detail of facies articularis caudalis of T. waltonensis (l), T. alba $(\mathbf{m})$, and P. erithacus $(\mathbf{n})$; the dotted lines indicate the shape of the facies articularis caudalis. $\mathbf{o}-\mathbf{q}$ Cervical vertebra of $T$. waltonensis in dorsal (o), right dorsolateral (p), and caudal (q) view. $\mathbf{r}$ 9th cervical vertebra of $P$. erithacus in caudal view. $\mathbf{s}-\mathbf{u}$ Cervical vertebra of $T$. waltonensis in dorsal (s), ventral (t), and caudal (u) view. $\mathbf{v}-\mathbf{y}$ Cervical vertebra of T. waltonensis in dorsal (v), ventral (w), caudal (x), and left lateral (y) view. $\mathbf{z}-\mathbf{c c}$ Cranial thoracic vertebra of $T$. waltonensis in right lateral (z), left lateral (aa), caudal (k), and ventral (cc) view. dd-hh Thoracic vertebra of T. waltonensis in left lateral (dd), right lateral (ee), cranial (ff), cau- dal (gg), and craniodorsal (hh) view. ii, jj Caudalmost thoracic vertebra of T. alba (ii), and P. erithacus (ij) in left lateral view. kk-nn Caudalmost thoracic vertebra of T. waltonensis in right lateral (kk), cranial (ll), caudal (mm), and dorsal (nn) view. oo-qq Caudalmost thoracic vertebra of T. alba (oo) and P. erithacus (pp, qq) in cranial (pp) and caudal (oo, qq) view. The dotted frames indicate individual vertebrae that are shown in different views. The fossil vertebrae were coated with ammonium chloride. $c c l$ concavitas lateralis, $d p r$ ovate depressions (pleurocoels) on the lateral surface of vertebral corpus, $f c d$ facies articularis caudalis, $f c r$ facies articularis cranialis, $f t v$ foramen transversum, $f v t$ foramen vertebrale, icf incisura fossae, liz lacuna interzygapophysialis, pac processus articularis caudalis, prc processes formed by zygapophysis cranialis and zygapophysis caudalis, $p s p$ processus spinosus, $p t v$ processus transversus, $p v e$ processus ventralis, $t r d$ torus dorsalis, $z c d$ zygapophysis caudalis, $z c r$ zygapophysis cranialis. Scale bars equal $5 \mathrm{~mm}$; same horizontal scale bar for all fossil vertebrae, $\mathbf{l}-\mathbf{n}$ are not to scale 

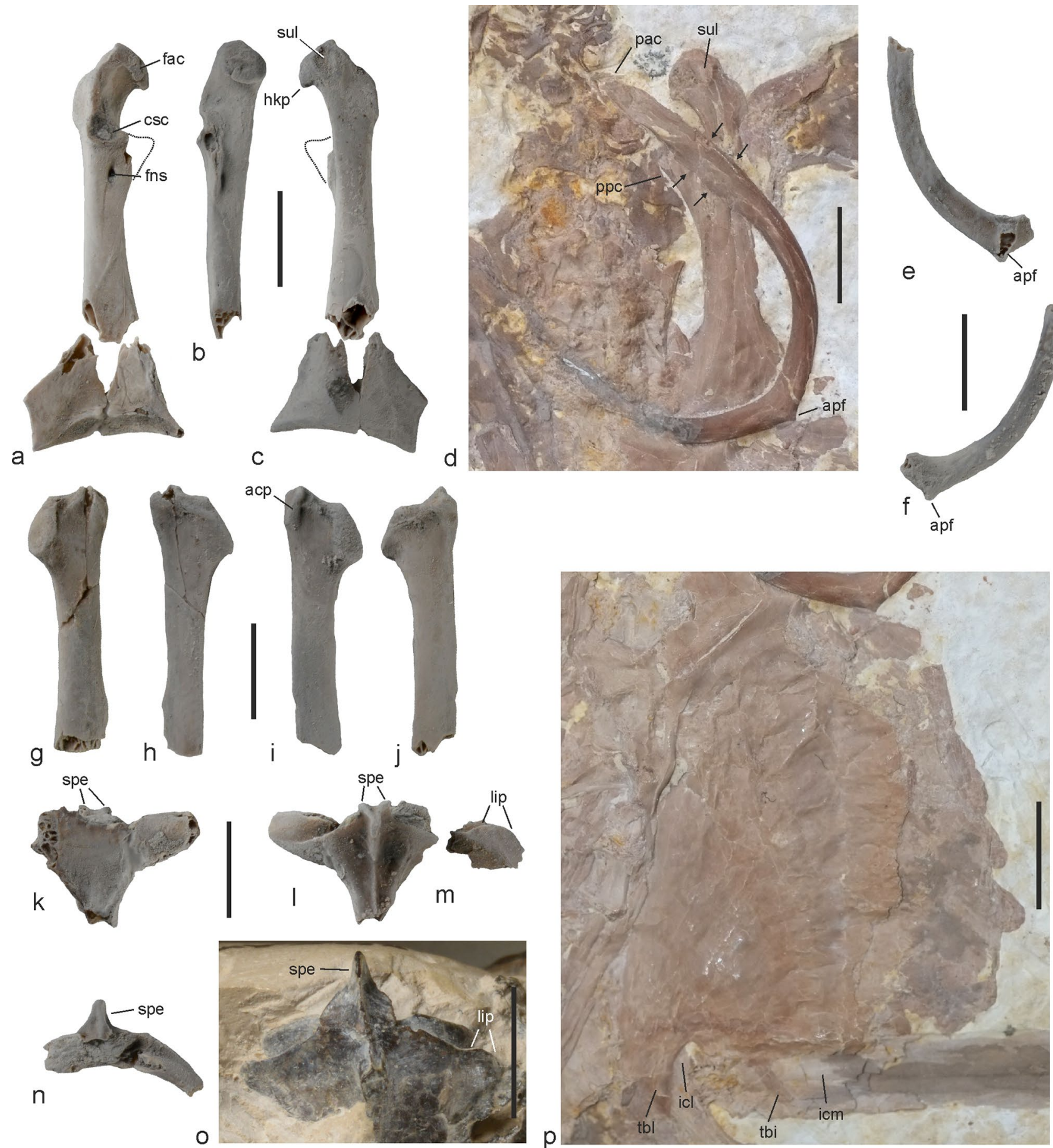

Fig. 5 Tynskya waltonensis sp. nov. from the early Eocene London Clay of Walton-on-the-Naze (SMF Av 652), pectoral girdle bones and sternum. a-c Partial left coracoid in dorsal (a), medial (b), and ventral (c) view, the dotted line indicates the reconstructed shape of the processus procoracoideus. d The coracoid (ventral view) and furcula of the T. eocaena holotype (SNSB-BSPG 1997 I 6, counter slab); the arrows denote the widening of the scapus claviculae. e, $\mathbf{f}$ Partial furcula in caudal (e) and cranial (f) view. g-j Cranial portions of the left $(\mathbf{g}, \mathbf{h})$ and right $(\mathbf{i}, \mathbf{j})$ scapula. $\mathbf{k}-\mathbf{n}$ Cranial fragment of the sternum in dorsal (k), ventral (l), and cranial (n) view; $\mathbf{m}$ is a fragment from the left side of the bone, in which the ventral lip formed by the lateral part of the sulcus coracoideus is preserved. o Cranial por-

tion of the sternum of an unidentified halcyornithid from the London Clay in ventral view (SMF Av 508; see Mayr 2007). p Sternum of the T. eocaena holotype (SNSB-BSPG 1997 I 6, counter slab). Fossil bones from the London Clay were coated with ammonium chloride. acp dorsal process formed by acromion, apf apophysis furculae, csc cotyla scapularis, fac facies articularis clavicularis, fns foramen nervi supracoracoidei, $h k p$ hook-like process formed by medial portion of processus acrocoracoideus, $\mathrm{icl}$ incisura lateralis, $\mathrm{icm}$ incisura medialis, lip ventral lip formed by lateral part of sulcus coracoideus, pac processus acromialis, $p p c$ processus procoracoideus, spe spina externa, sul sulcus on ventral surface of processus acrocoracoideus, $t b i$ trabecula intermedia, $t b l$ trabecula lateralis. Scale bars equal $5 \mathrm{~mm}$ 


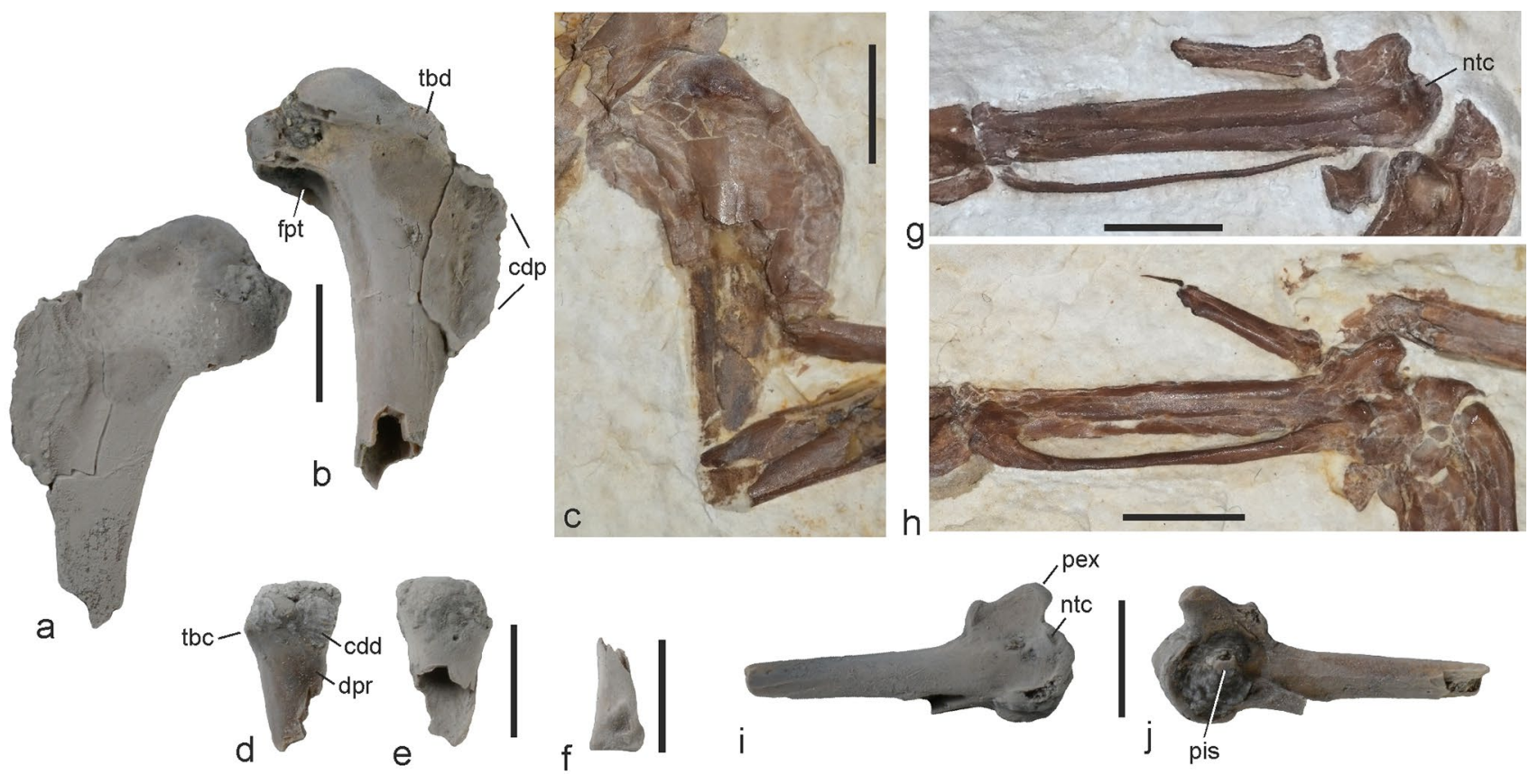

Fig. 6 Tynskya waltonensis sp. nov. from the early Eocene London Clay of Walton-on-the-Naze (SMF Av 652), wing bones in comparison to those of T. eocaena. a, b Proximal end of the right humerus in cranial (a) and caudal (b) view. c Proximal end of the right humerus of the T. eocaena holotype in caudal view (SNSB-BSPG 1997 I 6, main slab). d, e Distal end of left ulna in ventral (d) and dorsal (e) view. f Proximal end of right radius in ventral view. $\mathbf{g}$, $\mathbf{h}$ Hand section of left (g) and right (h) wing of the T. eocaena holotype in dorsal (g)

The other three cervical vertebrae (Fig. 4o-q, r-y) have short zygapophyses caudales that exhibit distinct tori dorsales and are separated by a deep lacuna interzygapophysialis. In their overall proportions, they correspond with the cervical vertebrae of Messelastur gratulator, the specimens of which do not allow a close examination of vertebral features (Peters 1994; Mayr 2005). The morphology of the articulation facets of the cervical vertebrae of the Halcyornithidae is likewise unknown.

The thoracic vertebrae preserved in SMF Av 652 are two adjacent cranial ones (Fig. 4z-hh) and one of the caudalmost thoracics (Fig. 4kk-nn). The cranial thoracics, which, by comparison with extant Accipitridae, are the 15th/16th or 16 th/17th praesacral vertebrae depending on the total vertebral count, had processus ventrales, even though these processes are broken in the fossils. The corpus of one of these vertebrae exhibits distinct pleurocoels (ovate fossae) on its lateral surfaces (Fig. 4dd, ee). The caudal thoracic vertebra (Fig. 4kk-nn) is nearly platycoelous and has almost flat rather than saddle-shaped articular surfaces; this caudal thoracic vertebra also exhibits well-developed pleurocoels. Unlike in the stem group strigiform Primoptynx from the early Eocene of Wyoming (Mayr et al. 2020), the vertebral corpus does not show pneumatic foramina. and ventral (h) view (SNSB-BSPG 1997 I 6, main slab). i, j Proximal end of left carpometacarpus in dorsal (i) and ventral (j) view. Fossil bones from the London Clay were coated with ammonium chloride. $c d d$ condylus dorsalis, $c d p$ crista deltopectoralis, $d p r$ depressio radialis, $f p t$ fossa pneumotricipitalis, $n t c$ notch in proximocranial margin of trochlea carpalis, pex processus extensorius, pis processus pisiformis, $t b c$ tuberculum carpale, $t b d$ tuberculum dorsale. Scale bars equal $5 \mathrm{~mm}$

The coracoid is poorly exposed in the main slab of the holotype of T. eocaena, so that only a few features of the bone could be observed by Mayr (2000). The holotype of T. waltonensis includes the left coracoid, which is broken in two pieces and lacks the processus procoracoideus and a section of the shaft (Fig. $5 \mathrm{a}-\mathrm{c}$ ). The bone closely resembles the coracoid of Messelastur and as in the latter taxon (Mayr 2011), it exhibits a large foramen nervi supracoracoidei and a deeply excavated, cup-shaped cotyla scapularis. The small facies articularis clavicularis overhangs the sulcus supracoracoideus. The processus acrocoracoideus is comparatively short and bears a sulcus on its ventral surface (Fig. 5c); this sulcus is also visible on the coracoid of the previously unstudied counter slab of the T. eocaena holotype (Fig. 5d). Compared with T. eocaena, the processus acrocoracoideus of $T$. waltonensis is somewhat narrower and the facies articularis clavicularis forms a better defined medial hook. The processus procoracoideus is broken in the London Clay fossil, but the counter slab of T. eocaena shows that this process is well developed (contra Mayr 2000, who tentatively assumed that is was short). The previously undescribed sternal extremity of the bone has a long processus lateralis, which is, however, not very extensive in sterno-omal direction and terminates with a straight margin. 

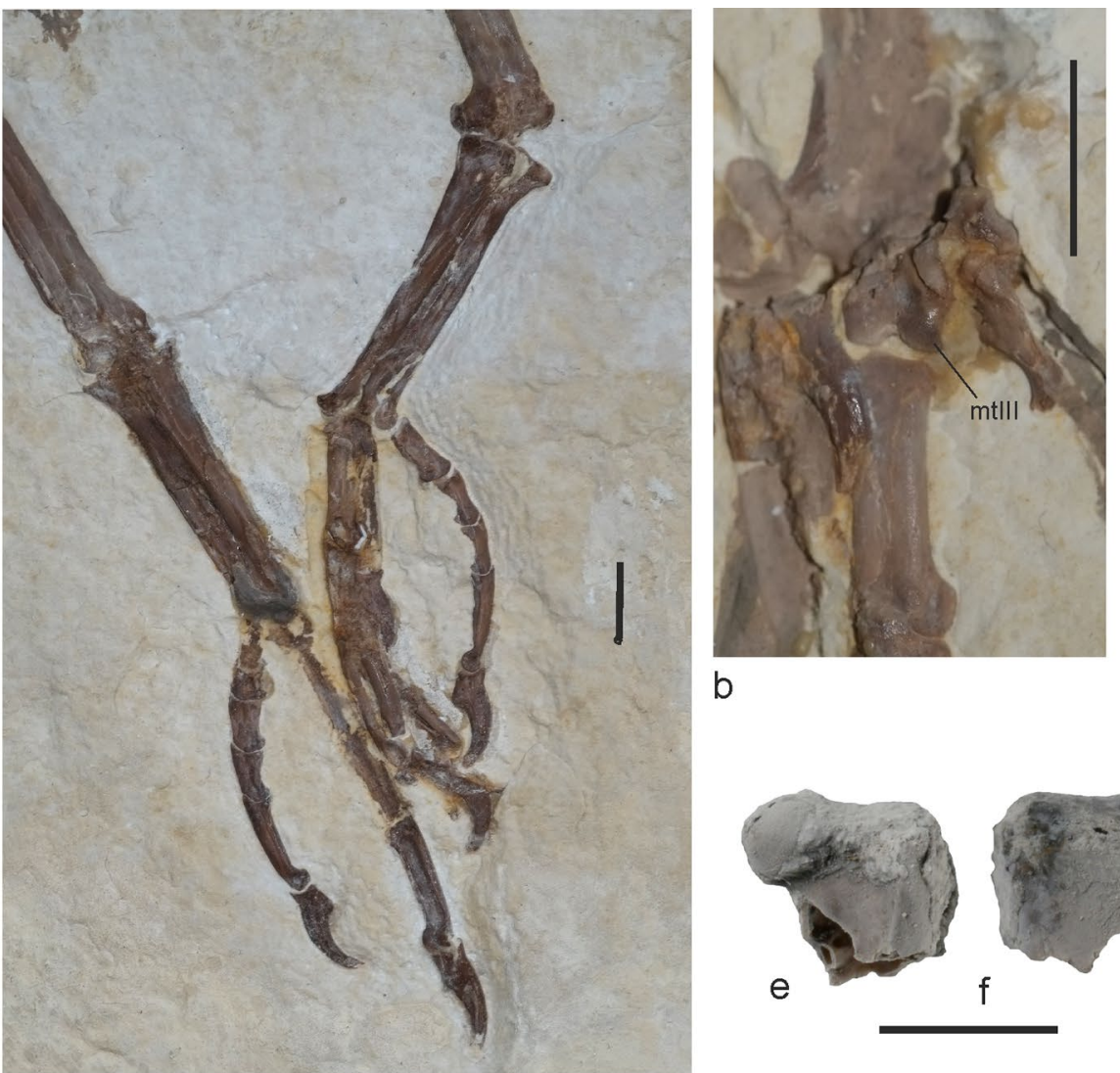

b
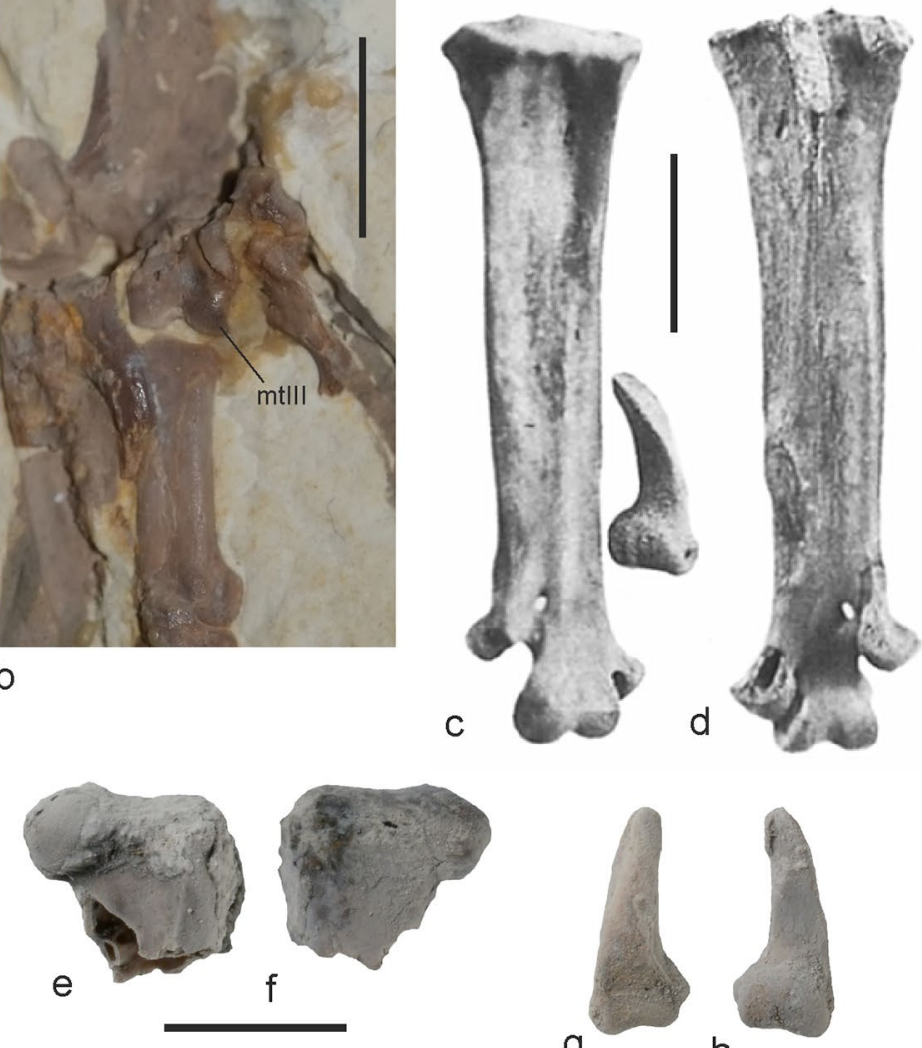

$\mathrm{h}$
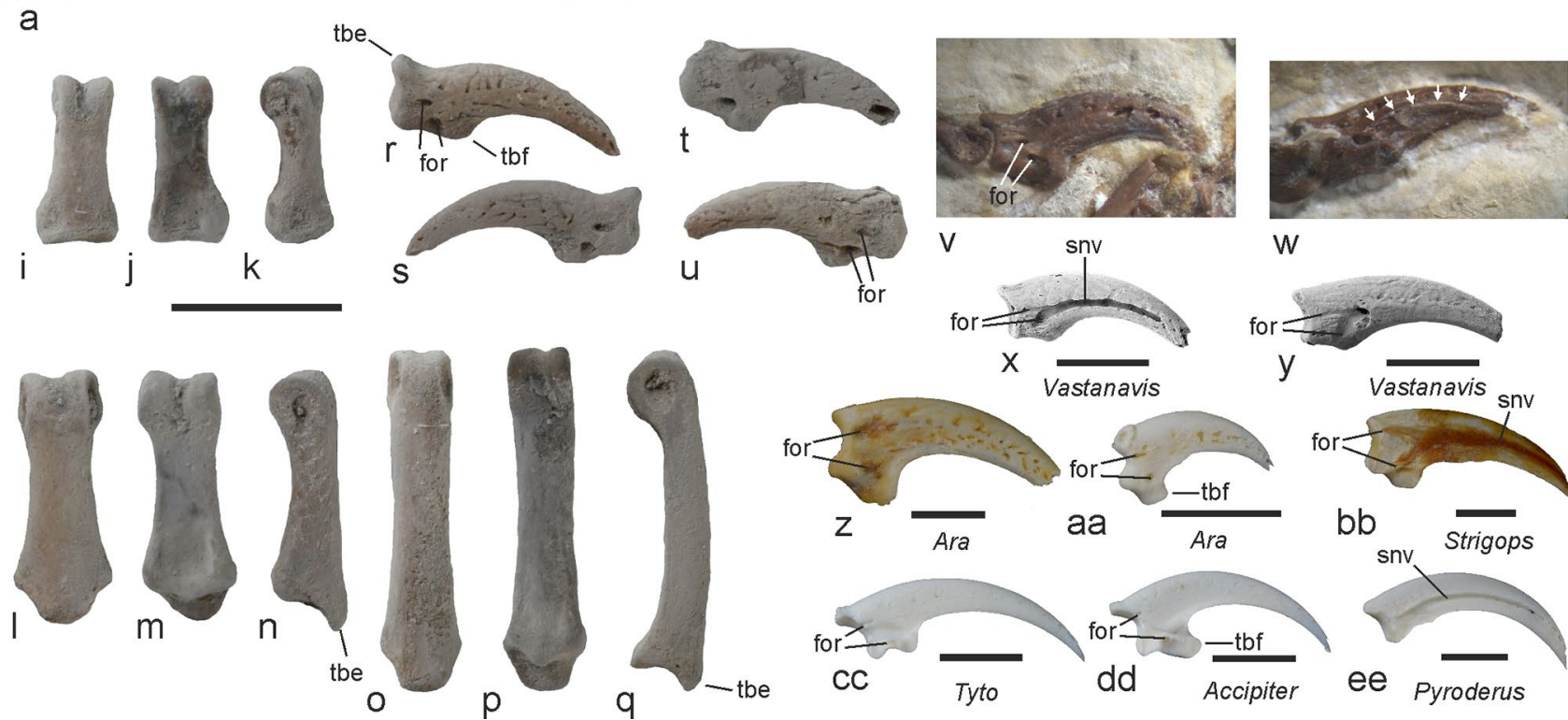

W
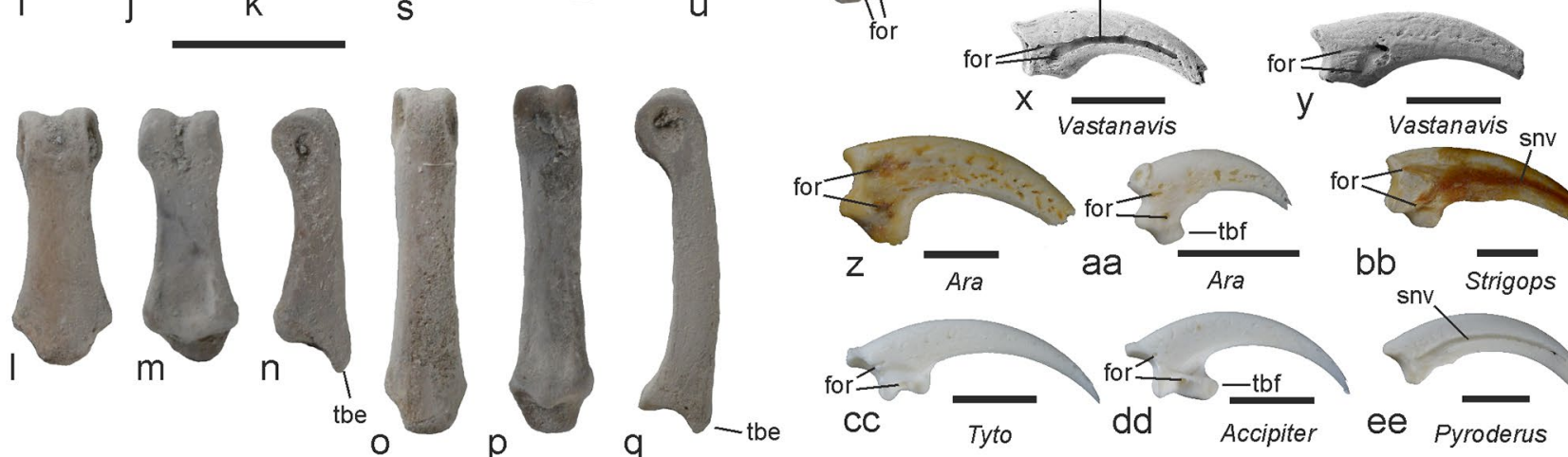

q

Compared with the Halcyornithidae, the coracoid of Tynskya has a proportionally longer omal extremity, a more deeply excavated cotyla scapularis, and a differently shaped processus lateralis (which forms a pointed tip in halcyornithids; Mayr 1998; Ksepka et al. 2011).

The extremitas sternalis of the furcula of SMF Av 652 bears a small, ridge-like apophysis (Fig. 5e, f). Only the impression of the furcula is preserved on the main slab of the holotype of T. eocaena, but a significant portion of the bone is present on the previously undescribed counter slab (Fig. 5d). The sternal extremity closely resembles that of the fossil from Walton-on-the-Naze and the omal extremity exhibits a long processus acromialis. However, in the holotype of T. eocaena, the scapus of the furcula widens in its omal section; this morphology is absent in the holotype 
४Fig. 7 Tynskya waltonensis sp. nov. from the early Eocene London Clay of Walton-on-the-Naze (SMF Av 652), leg bones in comparison to those of T. eocaena and other fossil and extant taxa. a Feet of the T. eocaena holotype (SNSB-BSPG 1997 I 6, main slab). b Detail of the distal end of the left tarsometatarsus of the T. eocaena holotype in dorsal view to show the shape of the wide trochlea metatarsi III (SNSB-BSPG 1997 I 6 counter slab; note that the shaft of the bone has been fabricated). c, d Right tarsometatarsus of $T$. waltonensis from Walton-on-the-Naze in dorsal (c, with associated os metatarsale I) in dorsal (c) and plantar (d) view (from Mayr 2000; the specimen is in a private collection). e, f Proximal end of left femur in caudal (e) and cranial (f) view. g, h Left os metatarsale I in dorsal (g) and plantar (h) view. i-k First phalanx of second toe in dorsal (i), plantar (j), and lateral (k) view. l-n Second phalanx of third toe in dorsal (l), plantar (m) and lateral (n) view. o-q Third phalanx of third toe in dorsal (o), plantar (p) and lateral (q) view. r-u two ungual phalanges $(\mathbf{r}, \mathbf{s}$ and $\mathbf{t}, \mathbf{u})$ in different views. $\mathbf{v}, \mathbf{w}$ Ungual phalanges of the left foot of the T. eocaena holotype (SNSB-BSPG 1997 I 6, main slab; v: ungual of fourth toe, w: ungual of third toe); the arrows in $\mathbf{w}$ denote the ridge along the medial surface of the phalanx. $x$-ee Ungual phalanges of other fossil and extant taxa: $\mathbf{x}, \mathbf{y}$ Vastanavis sp. (Vastanavidae) from the early Eocene of India (x: GU/RSR/VAS 1811, y: GU/ RSR/VAS 1813) and extant $\mathbf{z}$ Ara macao (Psittaciformes, Psittacidae), aa A. nobilis, bb Strigops habroptilus (Psittacidae), cc Tyto alba (Strigiformes, Tytonidae), dd Accipiter nisus (Accipitriformes, Accipitridae), ee Pyroderus scutatus (Passeriformes, Cotingidae). for bipartite proximal openings/proximal bifurcation of sulcus neurovascularis, snv sulcus neurovascularis, mtIII trochlea metatarsi III, tbe tuberculum extensorium, tbf tuberculum flexorium. Scale bars equal $5 \mathrm{~mm} ; \mathbf{v}$ and $\mathbf{w}$ are not to scale

of T. waltonensis, in which the furcular scapus has an equal width in the preserved omal portion.

The cranial end of the scapula (Fig. $5 \mathrm{~g}-\mathrm{j}$ ) compares well with the holotype of T. eocaena. The short acromion exhibits a small dorsal process, which was also noted in the original description of Tynskya eocaena (Mayr 2000). The welldeveloped tuberculum coracoideum corresponds with the presence of a deep cotyla scapularis on the coracoid.

The cranial fragment of the sternum preserved in SMF Av 652 (Fig. 5k-n) bears a short spina externa with a weakly bifurcated tip. In the Halcyornithidae, the spina externa is proportionally long and its tip not bifurcated (Mayr 2007; Fig. 5o). The lateral part of the sulcus coracoideus forms a ventral lip. A fragment of the margo costalis shows two processus costales. No data on the morphology of the sternum can be obtained from the main slab of the T. eocaena holotype, but the counter slab allows the recognition of some details of the caudal margin and two shallow incisions in the right half of the bone can be discerned (Fig. 5p).

The proximal end of the right humerus (Fig. 6a, b) also closely resembles the $T$. eocaena holotype. As in the latter, the crista deltopectoralis is comparatively large and the tuberculum dorsale is small and located near the proximal margin of the bone. The fossa pneumotricipitalis is filled with pyrite in the holotype of $T$. waltonensis, but the humerus of the T. eocaena holotype (Fig. 6c) shows that it lacked pneumatic foramina (Mayr 2000).
Even though the distal end of the left ulna is preserved in SMF Av 652 (Fig. 6d, e), its surface is partially covered with a pyrite layer. Therefore, it cannot be discerned whether there is a deep depression next to the incisura tendinosa, which was described for Messelastur by Mayr (2011). The depressio radialis is only moderately developed, whereas it is marked in the Halcyornithidae (Mayr 1998, 2000). The tuberculum carpale is very small. The proximal end of the radius (Fig. 6f) exhibits a non-descript morphology and no features of potential phylogenetic significance could be identified.

The proximal end of the left carpometacarpus (Fig. 6i, j) is also partly covered with pyrite, which obscures morphological details. However, in those features that can be discerned, it closely resembles the holotype of T. eocaena, even though the tip of the processus extensorius is somewhat more proximally directed (compare Figs. $6 \mathrm{~g}$ and i). On the dorsal surface of the bone, there is a small but distinct notch in the proximocranial margin of the trochlea carpalis, presumably for musculus ulnometacarpalis ventralis, which is also present in the holotype of $T$. eocaena (Fig. $6 \mathrm{~g}$; the corresponding part of the carpometacarpus is unknown for Messelastur).

The proximal end of the left femur (Fig. 7e, f) is likewise largely covered with a pyrite layer. Only few osteological details are therefore visible, but the crista trochanteris is weakly developed and there is no pneumatic foramen in the cranial portion of the bone.

SMF Av 652 includes five pedal phalanges, two of which are unguals (Fig. 7i-u). The smallest non-ungual phalanx has an asymmetric proximal end and is identified as the first phalanx of the second toe (the rounded distal trochlea distinguishes it from the first phalanx of the fourth toe of the T. eocaena holotype; see Fig. 7a). The second toe is hardly exposed in the T. eocaena holotype and the London Clay fossil shows that the proximal phalanx of this toe is shortened as it is in Messelastur, with which it also corresponds in overall shape. Two other phalanges are considered to be the second and third phalanges of the third toe (Fig. 71-q). As in the holotype of $T$. eocaena, both phalanges bear a strongly developed tuberculum extensorium, which projects well beyond the articular cotyla; the second phalanx is furthermore dorsoventrally flattened. The two ungual phalanges (Fig. $7 \mathrm{r}-\mathrm{u}$ ) have an ovate cross section and appear to have been sharply pointed. As in owls, accipitrid diurnal birds of prey, and some parrots, the sulci neurovasculares of the two ungual phalanges of SMF Av 652 are laterally closed and open with foramina next to the tuberculum flexorium; this condition is also visible in the holotype of T. eocaena (Fig. 7v, w) and in Messelastur gratulator, but went unnoticed by Mayr (2000, 2011). In the fossil phalanges from the London Clay as well as in the T. eocaena holotype, each of these foramina is dorsally flanked by another, somewhat 
smaller but still well-developed foramen (Fig. 7u, v, r). These additional dorsal foramina are likewise present in owls (Fig. 7cc) and accipitrids (Fig. 7dd), in which they are, however, much smaller and very inconspicuous (Mosto and Tambussi 2014). In crown group Psittaciformes (Fig. 7zbb) the sulcus neurovascularis also bifurcates proximally and opens with two foramina in taxa with a closed sulcus (e.g., Ara, Amazona; Fig. 7zz, aa); in taxa with an open sulcus (e.g., Strigops, Psittacus), the bifurcation is well visible (Fig. 7bb). Closure of the neurovascular sulcus is variable in the Halcyornithidae, in which the sulcus is closed in Serudaptus, but open in the other taxa, in which the neurovascular sulcus does not bifurcate (Mayr 1998; Ksepka and Clarke 2012). The ungual phalanges of the putative stem-group psittaciform Vastanavis (Vastanavidae) from the early Eocene of India show some variability, but one of the three unguals reported by Mayr et al. (2013) lacks a closed neurovascular sulcus and the sulcus neurovascularis bifurcates (Fig. 7x, y; Mayr et al. 2013). Ungual phalanges similar to those of Tynskya also occur in the putative stem psittaciform Avolatavis tenens from the Green River Formation (Ksepka and Clarke 2012) and in an Avolatavis-like fossil from the London Clay figured by Mayr and Daniels (1998: fig. 6c). In crown group Psittaciformes, the unguals are more compressed and the tuberculum flexorium is more pronounced. In owls (including the early Eocene stem-group taxon Primoptynx; Mayr et al. 2020) and diurnal birds of prey, the articular cotyla is more concave, the tuberculum extensorium less dorsally directed, and the tuberculum flexorium more prominent.

The os metatarsale I (Fig. 7g, h) closely resembles that of the holotype of Tynskya eocaena and unlike in strigiform birds it exhibits a very long processus articularis tarsometatarsalis. An equally long processus articularis tarsometatarsalis occurs in the Halcyornithidae (Mayr 2002).

\section{Results of the phylogenetic analysis}

The primary analysis of the character matrix in the appendix resulted in 14 most parsimonious trees $(L=232$; CI 0.36; $\mathrm{RI}=0.60)$. The consensus tree is largely unresolved (Fig. 8a), but supports a sister group relationship between Tynskya and Messelastur as well as a sister group relationship between the Messelasturidae and the Halcyornithidae (the latter was, however, not retained in the bootstrap analysis). Characters that were optimized as apomorphies of the Messelasturidae in the analysis include dorsoventrally deep mandibular rami (ch. 7), a trochlea metatarsi IV with a plantarly directed, wing-like flange (ch. 66), an abbreviated proximal phalanx of the second toe (ch. 69), as well as laterally closed sulci neurovasculares of the ungual pedal phalanges (ch. 71). Characters that were optimized as synapomorphies of messelasturids and halcyornithids include pleurocoelous thoracic vertebrae (ch. 15), the absence of pneumatic foramina in the fossa pneumotricipitalis of the humerus (ch. 31), as well as a tarsometatarsus with widely separated foramina vascularia proximalia (ch. 56) and a wide trochlea metatarsi III (ch. 63) that bears a tubercle on its lateral side (ch. 65). Messelasturids and halcyornithids also share long processus supraorbitales, the presence of which has, however, yet to be confirmed for Tynskya (the corresponding skull area is poorly preserved in the holotype of $T$. eocaena); long supraorbital processes (ch. 3) were, furthermore, optimized as a synapomorphy of messelasturids and halcyornithids in only some of the trees, but as an apomorphy of a more inclusive clade in others.

With regard to the interrelationships of the extant taxa, all of the resultant trees conflict with well-supported tree topologies derived from molecular data (Ericson et al. 2006; Hackett et al. 2008; Jarvis et al. 2014; Prum et. al. 2015; Kuhl et al. 2021). In eight of the 14 trees, Messelasturidae and Halcyornithidae resulted in a clade together with Strigiformes and the falconiform Falconidae, with the latter two taxa being widely separated in molecular phylogenies. In six trees, a clade including Psittaciformes, Messelasturidae, and Passeriformes was obtained. Even though close affinities between Psittaciformes and Passeriformes conform with molecular phylogenies, the analysis did not support a sister group relationship between this clade and the Falconidae.

The analysis that was constrained by a molecular scaffold resulted in six most parsimonious trees ( $L=257$; CI 0.40 ; $\mathrm{RI}=0.62$ ), the strict consensus tree of which is shown in Fig. 8b. In this analysis, a sister group relationship between Messelasturidae and Halcyornithidae was not retained, and halcyornithids were not recovered as monophyletic. Instead, messelasturids, Serudaptus, and the halcyornithid taxa Cyrilavis and Pseudasturides resulted as successive sister taxa of a clade including crown group Psittaciformes and Passeriformes.

\section{Discussion}

\section{Phylogenetic affinities}

The new osteological data and the analysis of the emended character matrix corroborate a sister group relationship between Tynskya and Messelastur. Although deep mandibular rami were listed in previous diagnoses of the Messelasturidae (Mayr 2005, 2011), the mandible has so far only been described for Messelastur, and the holotype of $T$. waltonensis for the first time confirms the presence of deep rami for the taxon Tynskya. Other derived features shared by Tynskya and Messelastur include a characteristic tarsometatarsus morphology with a single hypotarsal sulcus and 


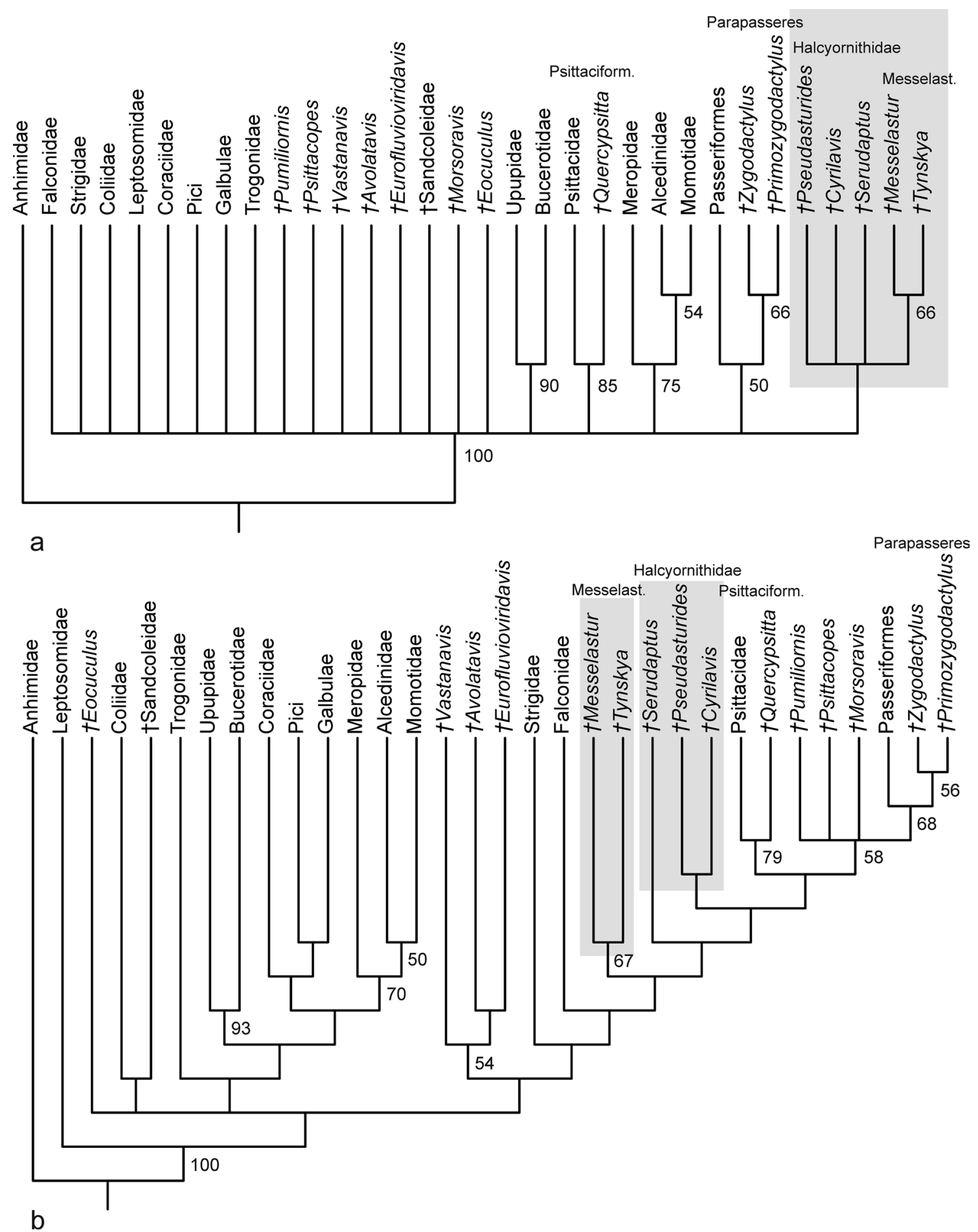

Fig. 8 a Strict consensus tree of 14 most parsimonious trees $(L=232$; CI 0.36 ; $\mathrm{RI}=0.60)$ resulting from the primary phylogenetic analysis. b Strict consensus tree of six most parsimonious trees $(L=257$; CI $0.40 ; \mathrm{RI}=0.62)$ resulting from the analysis that was con-

a very wide trochlea metatarsi III (visible on the counter slab of the T. eocaena holotype; Fig. 7b), superficially "raptorlike" ungual pedal phalanges with an ovate cross section strained to a molecular scaffold. Bootstrap support values $>50 \%$ are shown next to the nodes. The clade including Messelasturidae and Halcyornithidae is highlighted in grey; extinct taxa are indicated by a dagger

and closed neurovascular sulci (which were erroneously considered to be an autapomorphy of Messelastur by Mayr 2011), and a longitudinal ridge along the medial surface of 
the ungual phalanx of the third toe (this distinctive character was noted by Mayr 2011 for Messelastur and is here for the first time reported for Tynskya eocaena).

The phylogenetic affinities of messelasturids were controversially resolved in earlier analyses (Mayr 2011, 2015; Ksepka and Clarke 2012) and the present analyses were also sensitive to the relationships among the extant taxa. The new fossil furthermore underlines the mosaic nature of the skeletal morphology of messelasturids.

A previously unnoticed derived trait of the taxon Tynskya is the presence of platycoelous caudal thoracic vertebrae with flat articular facets. In most birds, these vertebrae are heterocoelous (saddle-shaped articular facets), whereas crown group Psittaciformes have opisthocoelous thoracic vertebrae with a convex cranial and a concave caudal articulation facet. This latter condition is likely to have evolved from a platycoelous stage in psittaciform stem group representatives, and platycoelous cervical vertebrae may therefore constitute further evidence for psittaciform affinities of the Messelasturidae. Otherwise, the osteology of messelasturids is very different from extant Psittaciformes and from other Eocene taxa considered to be putative stem-group representatives of the group (e.g., Vastanavis, Quercypsitta). The coracoid in particular is unlike that of Vastanavis and shows a closer resemblance to the coracoid of strigiform birds. This similarity may, however, well be due to the retention of plesiomorphic characteristics of a more inclusive clade comprising owls and parrots.

As in Messelastur, the ungual phalanges of Tynskya are superficially "raptor-like", with an ovate cross section and closed neurovascular sulci. Mayr (2011) considered this morphology to possibly be indicative of close affinities to strigiform birds, but, as detailed above, similar "raptor-like" ungual phalanges are known from various early Eocene putative stem-group Psittaciformes. Two further characters shared by messelasturids and strigiform birds are, however, not found in psittaciforms. One of these is a ridge along the medial surface of the ungual phalanx of the third toe, which otherwise only occurs in hawk-like diurnal raptors (Accipitridae). This medial ridge is marked in Messelastur gratulator (Mayr 2011: fig. 5b) and is also present in the holotype of $T$. eocaena, where it is, however, less pronounced (Fig. $7 \mathrm{w}$ ). The other derived characteristic shared with the Strigiformes concerns the presence of supraorbital processes, which are well developed in Messelastur (as detailed above, the occurrence of supraorbital processes cannot be assessed in both slabs of the holotype of T. eocaena, owing to the poor preservation of the corresponding skull part). These processes are reduced in extant Strigiformes, but they are well-developed in early Eocene stem group representatives of owls (Mayr 2017; Fowler et al. 2018). However, the medial ridge on the ungual phalanx of the third toe is not present in the Halcyornithidae, and supraorbital processes evolved several times independently in taxa of the Telluraves, which diminishes their phylogenetic value. The present analyses do not support closer affinities between messelasturids and strigiform birds.

Multiple analyses of molecular data suggest that the closest extant relatives of the Psittaciformes are the Passeriformes (passerines) and that the clade formed by parrots and passerines is the sister taxon of the Falconiformes (Ericson et al. 2006; Hackett et al. 2008; Jarvis et al. 2014; Prum et. al. 2015; Kuhl et al. 2021). Passeriformes have various extinct stem group representatives, so that zygodactyl feet are likely to be plesiomorphic for the clade including Psittaciformes and Passeriformes (Mayr 2009, 2015, 2017; Ksepka et al. 2019). If messelasturids are stem group representatives of this latter clade, as suggested by one earlier analysis (Mayr 2015: fig. 7c) and the constrained analysis of the present study, some of their raptor-like features, such as long supraorbital processes, a coracoid with a foramen nervi supracoracoidei, as well as ungual phalanges with closed neurovascular sulci, may be plesiomorphic. At present, however, this assumption remains mere speculation, not least because close affinities between messelasturids and the clade including Psittaciformes and Passeriformes are far from being well-established.

\section{Paleobiology}

Messelasturids appear to have been widespread in the early Eocene of Europe and North America and knowledge of their way of living would promote an understanding of past ecosystems. However, because no extant birds exhibit the combination of unusual features shown by these birds, the paleobiology of messelasturids is difficult to assess.

The shape of the ungual phalanges and the "raptor-like" beak of Messelastur gratulator prompted Peters (1994) and Mayr (2011) to hypothesize that the species had a predatory way of living. Even though similar ungual phalanges are now also known from other putative stem group Psittaciformes (Avolatavis, Vastanavis), the medial ridge on the ungual phalanx of the third toe is otherwise only found in predatory birds (Accipitriformes, Strigiformes).

Equally deep mandibular rami as in messelasturids, however, do not occur in any extant birds of prey, but are found in some granivorous passerines (e.g., species of the Fringillidae, Emberizidae, and Estrildidae). The mandibular morphology therefore suggests that the food of messelasturids included hard items that required strong bite forces. The mandibular rami of messelasturids are also superficially reminiscent of those of crown group Psittaciformes, but the mandibular symphysis of Tynskya is not as deeply concave as in parrots.

The holotype of $T$. waltonensis documents a distinctive morphology of the cervical vertebrae of messelasturids, 
which have concave rather than saddle-shaped caudal articulation facets. Whereas there exists variation in the shape of the articular facets of the cervical vertebrae in other tetrapod groups (e.g., turtles; Williams 1950), all extant birds have heterocoelous cervical vertebrae with saddle-shaped articular surfaces. Concave caudal articulation facets characterize opisthocoelous vertebrae, which in extant birds are, however, restricted to the thoracic series and only occur in a few taxa, that is, Psittaciformes, Sphenisciformes, and some Suliformes and Charadriiformes. The concave caudal articulation facets of the cervical vertebrae of Tynskya are also likely to have been functionally correlated with a particular ecomorphological characteristic of messelasturids.

The morphology of the proximal end of the humerus also informs the paleobiology of messelasturids, and of particular functional significance is the small and proximally located tuberculum dorsale. This tubercle serves as the attachment site of musculus supracoracoideus, which elevates the wing. The tuberculum dorsale is well-developed and often distally elongated in birds that are capable of powerful vertical takeoffs, such as extant landfowl, parrots, as well as doves and pigeons (Mayr and Scofield 2014). A small tuberculum dorsale, by contrast, is found in soaring birds and in birds that initiate their flight by leaps from elevated perches. The small tuberculum dorsale of the humerus of messelasturids indicates that these birds belonged to the latter group and did not have a strongly developed supracoracoideus muscle. Most likely, messelasturids therefore neither regularly searched for food on the ground, nor did they capture prey by sallying flights from perches.

Still, the above remarks indicate that messelasturids had a specialized feeding ecology. The derived morphology of the phalanges represents an adaptation for increased grasping capabilities and may indicate a raptorial ecology. Messelasturids may have been feeding on hard-shelled invertebrates, but other prey items and even fruits or seeds cannot be excluded as food resources. Early Eocene paratropical forests of the Northern Hemispheric differed from extant tropical ecosystems in various aspects and in light of the unusual specializations of messelasturids, it is well possible that these birds exploited a feeding niche that is no longer available to extant birds.

\section{Appendix 1}

\section{Character descriptions}

1. Skull, largely or completely ossified septum nasale: absent (0), present (1).

2. Beak with well-defined cere surrounding narial openings (feathered in some Psittacidae): no (0), yes (1).
3. Skull, os lacrimale with well developed, caudally projecting processus supraorbitales: absent (0), present (1).

4. Palatinum, crista ventralis: absent (0), present (1).

5. Well developed processus basipterygoidei, which articulate with the ossa pterygoidea: yes (0), no (1).

6. Mandible: large, ovate fenestra caudalis mandibulae: absent (0), present (1).

7. Mandible, rami dorsoventrally deep across the entire mandibular length: no (0), yes (1).

8. Mandible, area of pars symphysialis with rectangular cross section: absent (0), present (1).

9. Columella with large, hollow, bulbous basal and footplate area which exhibits a large fenestra on one side: no (0), yes (1).

10. Quadrate, condylus medialis with markedly concave lateral articular surface: no (0), yes (1).

11. Number of praesacral vertebrae: 20 or more (0), 18 or 19 (1).

12. Fourth cervical vertebra, osseous bridge connecting the processus transversus with the processus articularis caudalis: absent (0), present (1).

13. Fourth cervical vertebra, processus spinosus long and well defined: no (0), yes (1).

14. Fourth cervical vertebra, processus ventralis long and well defined: no (0), yes (1).

15. Corpus of thoracic vertebrae with distinct ovate fossae on lateral surfaces: no (0), yes (1).

16. Caudal thoracic vertebrae: heterocoelous (0), platycoelous (1), opisthocoelous (2).

17. Pygostyle with large, shield-like discus pygostyli with sharply defined, ridge-like lateral margins: no (0), yes (1).

18. Furcula with processus acrocoracoideus and processus acromialis well-developed, forming a plate-like extremitas omalis of subtriangular shape: no (0), yes (1).

19. Furcula, extremitas omalis with distinct, laterally protruding facies articularis acrocoracoidea: no (0), yes (1).

20. Furcula with well-developed apophysis furculae: no (0), yes (1).

21. Coracoid, facies articularis scapularis deeply excavated and cup-like: yes (0), no (1).

22. Coracoid, foramen nervi supracoracoidei: present (0), absent (1).

23. Coracoid, extremitas sternalis with notch in margo medialis: no (0), yes (1).

24. Coracoid, tip of processus acrocoracoideus broadly rounded: no (0), yes (1).

25. Coracoid, processus lateralis well-developed, with dorsal portion of facies articularis sternalis extending well beyond lateral margin of shaft of bone: yes (0), no (1). 
26. Scapula, acromion distinctly bifurcate, i.e. with an additional dorsal process: no (0), yes (1).

27. Sternum, well developed spina externa rostri: absent (0), present (1).

28. Caudal margin of sternum: with four notches/fenestrae (0), with two notches/fenestrae (1).

29. Humerus long and slender, with small proximal end: yes (0), no (1).

30. Humerus, processus flexorius prominent and reaching distally well beyond distal margin of condylus ventralis: no (0), yes (1).

31. Humerus, fossa pneumotricipitalis with pneumatic openings: yes (0), no (1).

32. Humerus, well-defined and strongly projected processus supracondylaris dorsalis: absent (0), present (1).

33. Ulna exceeding humerus in length: no (0), yes (1).

34. Ulna, cotyla ventralis greatly enlarged, extending into olecranon: no (0), yes (1).

35. Ulna, olecranon very long, narrow, and pointed; tuberculum ligamenti collateralis ventralis strongly protruding: no (0), yes (1).

36. Carpometacarpus, distinctly exceeding coracoid in length: no (0), yes (1).

37. Carpometacarpus, os metacarpale minus distinctly bowed, spatium intermetacarpale very wide: no (0), yes (1).

38. Carpometacarpus, well-developed protuberantia metacarpalis: absent (0), present (1).

39. Carpometacarpus, processus intermetacarpalis: absent or small (0), well developed, reaching the os metacarpale minus (1), absent but tendon of musculus extensor carpi ulnaris inserts on the os metacarpale minus as it does in taxa with a processus intermetacarpalis (2).

40. Carpometacarpus, ventral part of trochlea carpalis cranio-caudally narrow and proximodistally elongate, slanting caudally towards the midline of the caudal side, fovea carpalis caudalis marked: no (0), yes (1).

41. Carpometacarpus, os metacarpale minus distinctly exceeding os metacarpale majus in length: no (0), yes (1).

42. Os carpi radiale, proximodistally wide, with welldefined, narrow sulcus for the tendon of musculus extensor longus alulae: no (0), yes (1).

43. Phalanx proximalis digiti majoris, proximal end with large, proximally directing process: no (0), yes (1).

44. Pelvis, crista dorsolateralis ilii strongly developed, overhanging a marked concavitas infracristalis and convexly bowed in dorsal view; praeacetabular part much longer than postacetabular part, spina dorsolateralis ilii reduced: no (0), yes (1).

45. Pelvis, processus terminalis ischii very narrow and slender, touching pubis at an angle of $45^{\circ}-90^{\circ}$, fenestra ischiopubica very wide: no (0), yes (1).
46. Femur, pneumatic foramen on cranio-lateral side of proximal end: absent (0), present (1).

47. Femur, distal end thickened, tuberculum musculi gastrocnemialis lateralis large: no (0), yes (1).

48. Tibiotarsus, both cristae cnemiales and crista patellaris forming a ridge, which circumscribes a groove on the cranial side of the bone: no (0), yes (1).

49. Tibiotarsus, crista cnemialis cranialis continuous with a ridge opposite to the crista fibularis: no (0), yes (1).

50. Tibiotarsus, crista cnemialis lateralis distinctly hooked: no $(0)$, yes (1).

51. Tibiotarsus, distal end mediolaterally wide and craniocaudally compressed, trochlea cartilaginis tibialis shallow: no (0), yes (1).

52. Tarsometatarsus, not as follows (0), short and stocky, with distal width of bone measuring about one third of its length or more (1), greatly elongated, distinctly exceeding humerus in length (2).

53. Tarsometatarsus, crista plantaris lateralis: absent (0), present (1).

54. Tarsometatarsus, hypotarsus passing into a well developed crista medianoplantaris: no (0), yes (1).

55. Tarsometatarsus, fossa parahypotarsalis medialis marked and proximal part of margo medialis forming a sharp ridge: no (0), yes (1)

56. Tarsometatarsus, foramina vascularia proximalia widely separated, with lateral foramen situated farther proximally than medial one: no (0), yes (1).

57. Tarsometatarsus, hypotarsus, with closed, or nearly closed, canal for tendon of musculus flexor digitorum longus: no (0), yes (1), condition in Trogonidae, with common canal for tendons of musculus flexor digitorum longus, $\mathrm{m}$. flexor perforatus digiti 2 , and $\mathrm{m}$. flexor perforans et perforatus digiti 2 (2).

58. Tarsometatarsus, hypotarsus: not as follows (0), with marked, plantarly open furrow for tendon of musculus flexor hallucis longus (1), with closed, canal for tendon of musculus flexor hallucis longus (2). This character was coded as additive.

59. Tarsometatarsus, arcus extensorius (ossified retinaculum extensorium tarsometatarsi): absent (0), present (1).

60. Tarsometatarsus, canalis interosseus distalis: present (0), absent (1).

61. Tarsometatarsus, incisurae intertrochleares very short: no (0); yes (1).

62. Tarsometatarsus, trochlea metatarsi II: not as follows (0), enlarged, of subcylindrical shape, and with marked sulcus on plantar surface (1), with well-developed plantarly directed projection (2).

63. Tarsometatarsus, trochlea metatarsi III much wider in mediolateral than in dorsoplantar direction, its dorsal 
surface not being significantly raised above the dorsal surface of the shaft: no (0), yes (1).

64. Tarsometatarsus, trochlea metatarsi III with a deeply incised groove between the trochlear rims: no (0), yes (1).

65. Tarsometatarsus, trochlea metatarsi III with marked tubercle on lateral side: no (0), yes (1).

66. Tarsometatarsus, trochlea metatarsi IV: not as follows (0), with plantarly-directed, wing-like flange (1), with large trochlea accessoria that is not separated by a furrow from the main trochlea (2), with large trochlea accessoria that is separated by a furrow from the main trochlea (3). This character was coded as additive.

67. Hallux, proximal phalanx with proximal end greatly widened: no (0), yes (1).

68. Third and fourth toe coalescent at least over length of basal phalanx of third toe: no (0), yes (1).

69. Second toe, proximal phalanx abbreviated, measuring half the length of penultimate phalanx or less: no (0), yes (1).

70. Fourth toe, proximal three phalanges abbreviated, measuring less than half the length of fourth phalanx: no $(0)$, yes (1).

71. Ungual pedal phalanges, sulcus neurovascularis closed to form a canal that opens next to the tuberculum flexo- rium: no (0), yes (1). Vastanavis was scored variable for this character because some of the claws assigned to the taxon show closure of the sulcus neurovascularis, whereas others do not (Mayr et al. 2013).

72. Ungual phalanx of third toe with longitudinal ridge along medial surface: no (0), yes (1).

73. Musculus ambiens: present (0), absent (1).

74. Musculus flexor hallucis longus, origin with three heads, iliofibularis tendon passes lateral to lateral head: no (0), yes (1).

75. Musculus flexor hallucis longus, tendon supplying hallux: no (0), yes (1).

76. Tendon of musculus extensor digitorum longus sending branch to hallux: no (0), yes (1).

77. Phallus: present (0), absent (1).

\section{Appendix 2}

Character matrix used in the phylogenetic analysis; the matrix is based on Mayr (2015), revised or newly added characters are highlighted in bold. Anhimidae were specified as outgroup taxon; extinct taxa are indicated by a dagger. 
Taxa

Characters and character states

\begin{tabular}{llllllllllllllllllllllllll}
\hline 1 & 2 & 3 & 4 & 5 & 6 & $\mathbf{7}$ & 8 & 9 & $\mathbf{1 0}$ & 11 & $\mathbf{1 2}$ & $\mathbf{1 3}$ & $\mathbf{1 4}$ & 15 & $\mathbf{1 6}$ & 17 & 18 & 19 & 20 & 21 & 22 & 23 & 24 & 25 & 26
\end{tabular}

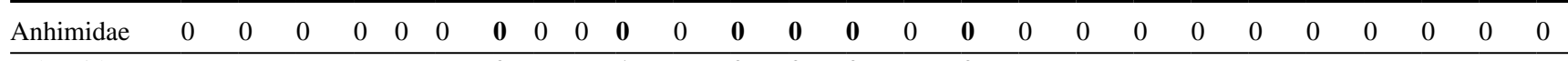

\begin{tabular}{lllllllllllllllllllllllllllll}
\hline Falconidae & 1 & 1 & 1 & 1 & 1 & 0 & $\mathbf{0}$ & 0 & 0 & $\mathbf{1}$ & 0 & $\mathbf{0}$ & $\mathbf{0}$ & $\mathbf{0}$ & 0 & $\mathbf{0}$ & 0 & 0 & 1 & 0 & 1 & 0 & 0 & 0 & 0 & 0
\end{tabular}

$\begin{array}{llllllllllllllllllllllllllllllll}\text { Strigidae } & 1 & 1 & 01 & 1 & 0 & 0 & \mathbf{0} & 0 & 0 & \mathbf{0} & 1 & \mathbf{0} & \mathbf{1} & \mathbf{0} & 0 & \mathbf{0} & 0 & 0 & 01 & 0 & 1 & 0 & 0 & 1 & 1 & 0\end{array}$

$\begin{array}{llllllllllllllllllllllllllllllll}\text { Psittacidae } & 1 & 1 & 0 & 1 & 1 & 01 & \mathbf{1} & 0 & 0 & \mathbf{0} & 1 & \mathbf{0} & \mathbf{1} & \mathbf{0} & 0 & \mathbf{2} & 0 & 0 & 0 & 0 & 1 & 1 & 0 & 1 & 1 & 0\end{array}$

$\begin{array}{llllllllllllllllllllllllllllllllll}\text { Coliidae } & 1 & 01 & 0 & 1 & 1 & 1 & \mathbf{0} & 0 & 0 & \mathbf{0} & 1 & \mathbf{0} & \mathbf{1} & \mathbf{0} & \mathbf{0} & \mathbf{0} & 1 & 1 & 0 & 1 & 1 & 1 & 0 & 1 & 1 & 0\end{array}$

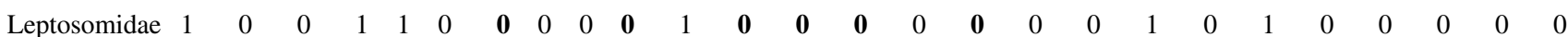

$\begin{array}{llllllllllllllllllllllllllllllll}\text { Alcedinidae } & 1 & 0 & 01 & 1 & 1 & 0 & \mathbf{0} & 0 & 1 & \mathbf{0} & 1 & \mathbf{1} & \mathbf{1} & \mathbf{0} & 0 & \mathbf{0} & 0 & 1 & 0 & 0 & 1 & 1 & 1 & 1 & 1 & 1\end{array}$

$\begin{array}{llllllllllllllllllllllllllllllllll}\text { Meropidae } & 1 & 0 & 0 & 1 & 1 & 0 & \mathbf{0} & 0 & 1 & \mathbf{0} & 1 & \mathbf{0} & \mathbf{0} & \mathbf{0} & 0 & \mathbf{0} & 0 & 1 & 0 & 0 & 1 & 1 & 0 & 0 & 0 & 1\end{array}$

$\begin{array}{llllllllllllllllllllllllllllllll}\text { Momotidae } & 1 & 0 & 0 & 1 & 1 & 0 & \mathbf{0} & 0 & 1 & \mathbf{0} & 1 & \mathbf{1} & \mathbf{0} & \mathbf{0} & 0 & \mathbf{0} & 0 & 0 & 0 & 0 & 1 & 1 & 0 & 1 & 1 & 1\end{array}$

$\begin{array}{llllllllllllllllllllllllllllllll}\text { Coraciidae } & 1 & 0 & 0 & 1 & 1 & 0 & \mathbf{0} & 0 & 0 & \mathbf{0} & 1 & \mathbf{0} & \mathbf{0} & \mathbf{0} & 0 & \mathbf{0} & 0 & 0 & 0 & 1 & 1 & 1 & 0 & 0 & 0 & 1\end{array}$

$\begin{array}{lllllllllllllllllllllllllllllllll}\text { Upupidae } & 1 & 0 & 0 & 1 & 1 & 0 & \mathbf{0} & 1 & 0 & \mathbf{0} & 1 & \mathbf{1} & \mathbf{1} & \mathbf{0} & 0 & \mathbf{0} & 1 & 0 & 0 & 0 & 1 & 1 & 0 & 0 & 0 & 1\end{array}$

$\begin{array}{lllllllllllllllllllllllllllllll}\text { Bucerotidae } & 1 & 0 & 0 & 1 & 1 & 0 & \mathbf{0} & 1 & 0 & \mathbf{0} & 1 & \mathbf{1} & \mathbf{0} & \mathbf{0} & 0 & \mathbf{0} & 1 & 0 & 0 & 0 & 1 & 1 & 0 & 0 & 0 & 0\end{array}$

$\begin{array}{lllllllllllllllllllllllllllllll}\text { Passeriformes } & 0 & 0 & 0 & 1 & 1 & 1 & \mathbf{0} & 0 & 0 & \mathbf{0} & 1 & \mathbf{1} & \mathbf{1} & \mathbf{1} & 0 & \mathbf{0} & 0 & 1 & 0 & 1 & 1 & 1 & 01 & 0 & 1 & 01\end{array}$

$\begin{array}{llllllllllllllllllllllllllllllll}\text { Pici } & 01 & 0 & 0 & 1 & 1 & 0 & \mathbf{0} & 0 & 0 & \mathbf{0} & 1 & \mathbf{1} & \mathbf{1} & \mathbf{0} & 0 & \mathbf{0} & 1 & 1 & 0 & 0 & 1 & 1 & 1 & 1 & 1 & 01\end{array}$

$\begin{array}{lllllllllllllllllllllllllllllllll}\text { Galbulae } & 1 & 0 & 0 & 1 & 1 & 01 & \mathbf{0} & 0 & 0 & \mathbf{0} & 1 & \mathbf{0} & \mathbf{0} & \mathbf{0} & 0 & \mathbf{0} & 1 & 0 & 1 & 1 & 1 & 1 & 1 & 0 & 0 & 0\end{array}$

$\begin{array}{lllllllllllllllllllllllllllllllllll}\text { Trogonidae } & 1 & 0 & 0 & 1 & 0 & 0 & \mathbf{0} & 0 & 1 & \mathbf{0} & 1 & \mathbf{0} & \mathbf{1} & \mathbf{0} & 0 & \mathbf{0} & 0 & 0 & 0 & 1 & 1 & 1 & 1 & 0 & 0 & 0\end{array}$

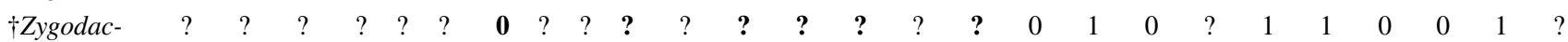

tylus

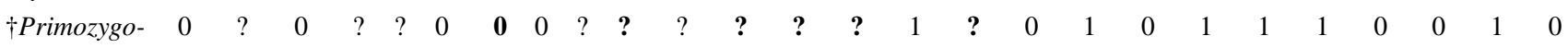
dactylus

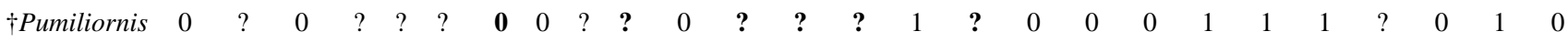

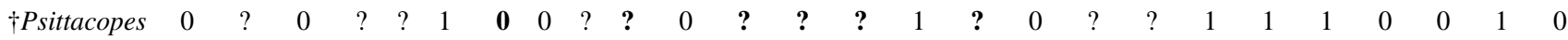

†Vastanavis ?

$\dagger$ Quercypsitta
$?$

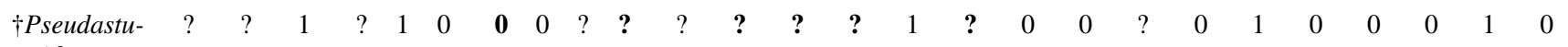

rides

$\begin{array}{lllllllllllllllllllllllllllllllll}\dagger \text { Cyrilavis } & 0 & ? & 1 & ? & ? & 0 & \mathbf{0} & 0 & ? & ? & 1 & \boldsymbol{?} & \boldsymbol{?} & \boldsymbol{?} & 1 & \boldsymbol{?} & 0 & 0 & 0 & 0 & 0 & 0 & 0 & 0 & 1 & 0\end{array}$

$\begin{array}{lllllllllllllllllllllllllllllllll}\dagger \text { Serudaptus } & ? & ? & ? & ? & ? & 0 & \mathbf{0} & 0 & ? & ? & ? & ? & ? & ? & ? & ? & ? & 0 & 0 & 0 & ? & ? & 0 & 0 & 1 & 0\end{array}$

$\begin{array}{llllllllllllllllllllllllllllllll}\dagger \text { Avolatavis } & ? & ? & ? & ? & ? & ? & ? & ? & ? & ? & ? & ? & ? & ? & ? & ? & 0 & ? & ? & ? & ? & ? & ? & ? & ? & ? & \text { ? }\end{array}$

$\begin{array}{llllllllllllllllllllllllllllllll}\dagger & \text { Eurofluvio- } & ? & ? & ? & ? & ? & 0 & \mathbf{0} & 0 & ? & ? & ? & ? & ? & ? & ? & ? & 0 & ? & ? & ? & ? & 0 & ? & \text { ? } & 0 & \text { ? }\end{array}$

viridavis

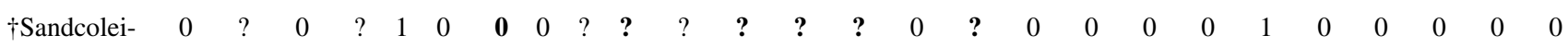
dae

$\begin{array}{llllllllllllllllllllllllllllllll}\dagger \text { Messelastur } & ? & ? & 1 & ? & ? & 0 & \mathbf{1} & 0 & ? & ? & ? & ? & ? & ? & ? & ? & 0 & 0 & 0 & 0 & 0 & 0 & 0 & 0 & 0 & 0\end{array}$

$\begin{array}{llllllllllllllllllllllllllll}\dagger \text { Tynskya } & ? & ? & ? & ? & ? & ? & 1 & 0 & ? & 1 & ? & 1 & 1 & 1 & 1 & 1 & ? & 0 & 0 & 0 & 0 & 0 & 0 & 0 & 0 & 0\end{array}$

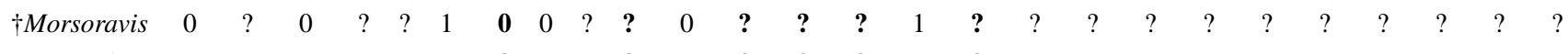

$\dagger$ †осисиlus ?

Taxa Characters and character states

\begin{tabular}{lllllllllllllllllllllllll}
\hline 27 & 28 & 29 & 30 & 31 & 32 & 33 & 34 & 35 & 36 & 37 & 38 & 39 & 40 & 41 & 42 & 43 & 44 & 45 & 46 & 47 & 48 & 49 & 50 & 51
\end{tabular}

\begin{tabular}{lllllllllllllllllllllllllllllll}
\hline Anhimidae & 0 & 1 & 0 & 0 & 0 & 0 & 0 & 0 & 0 & 1 & 0 & 0 & 0 & 0 & 0 & 0 & 0 & 0 & 0 & 1 & 0 & 0 & 0 & 1 & 0
\end{tabular}

$\begin{array}{lllllllllllllllllllllllllllll}\text { Falconidae } & 1 & 1 & 01 & 0 & 0 & 0 & 1 & 0 & 0 & 01 & 0 & 0 & 0 & 0 & 0 & 0 & 0 & 1 & 0 & 1 & 0 & 0 & 0 & 0 & 1\end{array}$

$\begin{array}{lllllllllllllllllllllllllllll}\text { Strigidae } & 0 & 0 & 0 & 0 & 0 & 0 & 1 & 0 & 0 & 0 & 0 & 0 & 0 & 0 & 0 & 0 & 0 & 1 & 0 & 0 & 0 & 0 & 0 & 0 & 1\end{array}$

$\begin{array}{lllllllllllllllllllllllllllll}\text { Psittacidae } & 1 & 1 & 1 & 0 & 0 & 0 & 1 & 0 & 0 & 01 & 0 & 0 & 0 & 0 & 0 & 0 & 0 & 0 & 0 & 0 & 0 & 0 & 1 & 0 & 1\end{array}$

$\begin{array}{lllllllllllllllllllllllllllllll}\text { Coliidae } & 1 & 0 & 1 & 1 & 1 & 0 & 0 & 1 & 0 & 0 & 1 & 0 & 1 & 0 & 1 & 0 & 0 & 0 & 0 & 0 & 1 & 1 & 1 & 0 & 0\end{array}$

$\begin{array}{lllllllllllllllllllllllllllll}\text { Leptosomi- } & 0 & 0 & 0 & 0 & 0 & 0 & 1 & 0 & 0 & 1 & 0 & 0 & 0 & 0 & 1 & 0 & 0 & 0 & 0 & 0 & 0 & 0 & 0 & 1 & 1\end{array}$

dae

$\begin{array}{lllllllllllllllllllllllllllll}\text { Alcedinidae } & 1 & 0 & 0 & 0 & 0 & 0 & 1 & 0 & 0 & 0 & 0 & 0 & 1 & 0 & 1 & 1 & 0 & 0 & 0 & 0 & 0 & 0 & 0 & 0 & 0\end{array}$

$\begin{array}{lllllllllllllllllllllllllllll}\text { Meropidae } & 1 & 0 & 0 & 0 & 0 & 0 & 1 & 0 & 0 & 0 & 0 & 0 & 0 & 0 & 1 & 1 & 0 & 0 & 0 & 0 & 0 & 0 & 0 & 0 & 0\end{array}$

\begin{tabular}{lllllllllllllllllllllllllll} 
Momotidae & 1 & 0 & 0 & 0 & 0 & 0 & 1 & 0 & 0 & 0 & 0 & 0 & 0 & 1 & 1 & 1 & 0 & 0 & 0 & 0 & 0 & 0 & 0 & 1 & 0 \\
\hline
\end{tabular} 
Taxa

Characters and character states

\begin{tabular}{lllllllllllllllllllllllll}
\hline 27 & 28 & 29 & 30 & 31 & 32 & 33 & 34 & 35 & 36 & 37 & 38 & 39 & 40 & 41 & 42 & 43 & 44 & 45 & 46 & 47 & 48 & 49 & 50 & 51
\end{tabular}

\begin{tabular}{llllllllllllllllllllllllllllll}
\hline Coraciidae & 1 & 0 & 0 & 0 & 0 & 0 & 1 & 0 & 0 & 0 & 0 & 0 & 1 & 0 & 0 & 1 & 0 & 0 & 0 & 0 & 0 & 0 & 0 & 0 & 0
\end{tabular} $\begin{array}{lllllllllllllllllllllllllllll}\text { Upupidae } & 1 & 1 & 1 & 1 & 0 & 0 & 1 & 0 & 1 & 0 & 1 & 1 & 2 & 1 & 1 & 1 & 0 & 0 & 1 & 1 & 0 & 0 & 0 & 0 & 0\end{array}$ $\begin{array}{llllllllllllllllllllllllllllll}\text { Bucerotidae } & 1 & 1 & 1 & 1 & 0 & 0 & 1 & 1 & 0 & 0 & 0 & 0 & 2 & 0 & 1 & 1 & 0 & 0 & 1 & 1 & 0 & 0 & 0 & 0 & 0\end{array}$ $\begin{array}{lllllllllllllllllllllllllllll}\text { Passeri- } & 1 & 1 & 1 & 1 & 0 & 1 & 1 & 0 & 1 & 0 & 0 & 1 & 1 & 1 & 1 & 0 & 0 & 0 & 0 & 0 & 0 & 0 & 1 & 1 & 0\end{array}$ formes

Pici

$\begin{array}{llllllllllllllllllllllllllllll}\text { Galbulae } & 1 & 0 & 0 & 0 & 0 & 0 & 1 & 0 & 0 & 0 & 0 & 1 & 1 & 1 & 1 & 1 & 1 & 0 & 0 & 0 & 0 & 0 & 0 & 0 & 0\end{array}$

$\begin{array}{llllllllllllllllllllllllllll}\text { Trogonidae } & 1 & 0 & 1 & 0 & 0 & 0 & 1 & 1 & 0 & 0 & 1 & 0 & 0 & 0 & 1 & 0 & 0 & 0 & 01 & 0 & 0 & 0 & 0 & 0 & 1\end{array}$

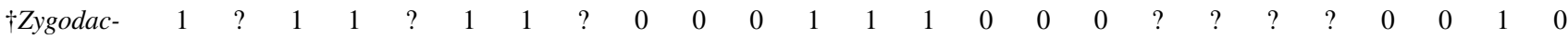

tylus

\begin{tabular}{|}
$\dagger$ Primozygo- & 1 & 0 & 1 & 1 & $?$ & 0 & 1 & $?$ & $?$ & 0 & 0 & 1 & 1 & 1 & 0 & 0 & 0 & $?$ & $?$ & $?$ & 0 & 0 & 0 & 1 & 0
\end{tabular} dactylus

$\begin{array}{llllllllllllllllllllllllllll}\dagger \text { Pumiliornis } & ? & 0 & 1 & 1 & ? & 0 & 1 & 0 & 0 & 0 & 0 & 0 & 0 & 0 & 0 & ? & 0 & ? & ? & ? & ? & 0 & 1 & 1 & 1\end{array}$

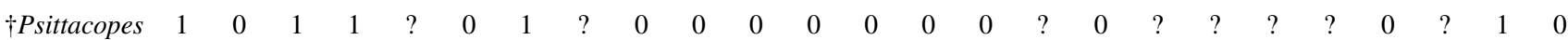

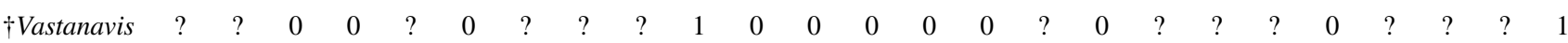
† Quercy- $\quad$ ? $\quad$ ? psitta

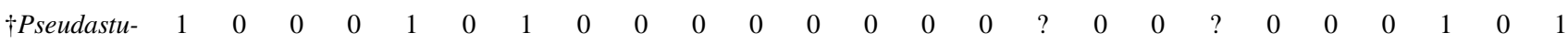
rides

$\dagger$ Cyrilavis $\quad ? \quad 00 \begin{array}{lllllllllllllllllllllllll} & 0 & 0 & ? & 0 & 1 & ? & 0 & 0 & 0 & 0 & 0 & 0 & 0 & 0 & 0 & 0 & 0 & ? & 0 & 0 & ? & 0 & 1\end{array}$

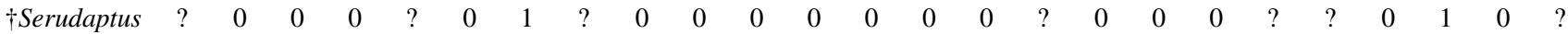

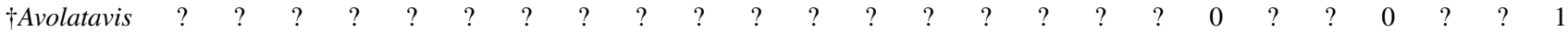

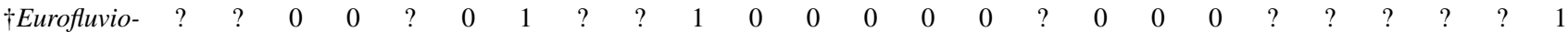
viridavis

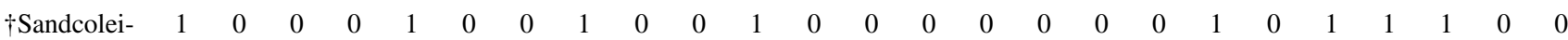
dae

$\begin{array}{llllllllllllllllllllllllllll}\dagger \text { Messelastur } & ? & ? & 0 & 0 & 1 & 0 & 1 & 0 & 0 & 0 & 0 & 0 & 0 & ? & 0 & 0 & 0 & ? & ? & 0 & ? & 0 & 0 & 0 & 1\end{array}$

$\begin{array}{lllllllllllllllllllllllllll}\dagger \text { Tynskya } & 1 & \mathbf{0} & \mathbf{0} & \mathbf{0} & \mathbf{1} & \mathbf{0} & \mathbf{1} & \mathbf{0} & \mathbf{0} & \mathbf{0} & \mathbf{0} & \mathbf{0} & \mathbf{0} & \mathbf{0} & \mathbf{0} & \mathbf{0} & \mathbf{0} & \boldsymbol{?} & \boldsymbol{?} & \mathbf{0} & \boldsymbol{?} & \mathbf{0} & \mathbf{0} & \mathbf{0} & ?\end{array}$ $\dagger$ Morsoravis ?

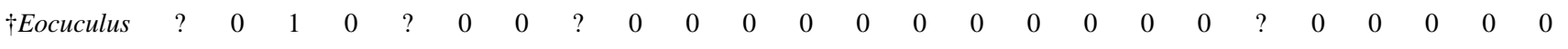

Taxa

Characters and character states

\begin{tabular}{llllllllllllllllllllllllll}
\hline 52 & 53 & 54 & 55 & 56 & 57 & 58 & 59 & 60 & 61 & 62 & 63 & 64 & 65 & 66 & 67 & 68 & 69 & 70 & 71 & $\mathbf{7 2}$ & 73 & 74 & 75 & 76 & 77
\end{tabular}

$\begin{array}{llllllllllllllllllllllllllll}\text { Anhimidae } & 0 & 0 & 0 & 0 & 0 & 0 & 0 & 0 & 0 & 0 & 0 & 0 & 0 & 0 & 0 & 0 & 0 & 0 & 0 & 0 & 0 & 0 & 0 & 0 & 0 & 0\end{array}$ $\begin{array}{llllllllllllllllllllllllllllllll}\text { Falconidae } & 02 & 0 & 1 & 0 & 0 & 0 & 0 & 0 & 0 & 0 & 0 & 0 & 0 & 0 & 0 & 0 & 0 & 1 & 1 & 1 & 0 & 0 & 0 & 0 & 0 & 1\end{array}$ $\begin{array}{lllllllllllllllllllllllllllllll}\text { Strigidae } & 0 & 0 & 0 & 0 & 0 & 0 & 0 & 01 & 0 & 0 & 0 & 0 & 0 & 0 & 1 & 0 & 0 & 01 & 1 & 1 & 1 & 1 & 0 & 0 & 0 & 1\end{array}$ $\begin{array}{llllllllllllllllllllllllllllll}\text { Psittacidae } & 01 & 0 & 0 & 0 & 0 & 1 & 2 & 0 & 1 & 0 & 1 & 1 & 1 & 1 & 3 & 0 & 0 & 01 & 1 & 01 & 0 & 01 & 0 & 0 & 1 & 1\end{array}$

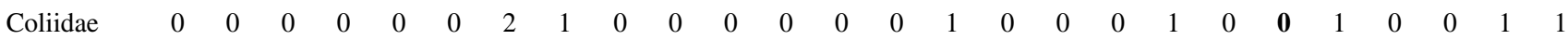
$\begin{array}{llllllllllllllllllllllllllllll}\text { Leptosomi- } & 0 & 0 & 0 & 0 & 0 & 1 & 2 & 0 & 0 & 0 & 0 & 0 & 0 & 0 & 1 & 0 & 0 & 0 & 0 & 0 & 0 & 1 & 0 & 0 & 0 & 1\end{array}$

dae

$\begin{array}{lllllllllllllllllllllllllllll}\text { Alcedinidae } & 1 & 0 & 1 & 1 & 0 & 1 & 0 & 0 & 1 & 0 & 0 & 0 & 0 & 0 & 0 & 1 & 1 & 0 & 0 & 0 & 0 & 1 & 0 & 1 & 0 & 1\end{array}$ $\begin{array}{lllllllllllllllllllllllllllllllll}\text { Meropidae } & 0 & 0 & 1 & 1 & 0 & 1 & 0 & 0 & 1 & 0 & 0 & 0 & 0 & 0 & 0 & 1 & 1 & 0 & 0 & 0 & 0 & 1 & 0 & 1 & 0 & 1\end{array}$ $\begin{array}{llllllllllllllllllllllllllllllll}\text { Momotidae } & 0 & 0 & 1 & 1 & 0 & 1 & 0 & 0 & 1 & 0 & 0 & 0 & 0 & 0 & 0 & 1 & 1 & 0 & 0 & 0 & 0 & 1 & 0 & 1 & 0 & 1\end{array}$ $\begin{array}{llllllllllllllllllllllllllllll}\text { Coraciidae } & 0 & 0 & 1 & 1 & 0 & 1 & 0 & 0 & 1 & 0 & 0 & 0 & 0 & 0 & 0 & 0 & 0 & 0 & 0 & 0 & 0 & 1 & 0 & 0 & 0 & 1\end{array}$ $\begin{array}{lllllllllllllllllllllllllllll}\text { Upupidae } & 0 & 0 & 1 & 1 & 0 & 1 & 2 & 1 & 1 & 1 & 0 & 0 & 0 & 0 & 0 & 0 & 1 & 0 & 0 & 0 & 0 & 1 & 0 & 0 & 0 & 1\end{array}$ $\begin{array}{llllllllllllllllllllllllllllll}\text { Bucerotidae } & 0 & 0 & 1 & 1 & 0 & 1 & 2 & 0 & 1 & 1 & 0 & 0 & 0 & 0 & 0 & 0 & 01 & 0 & 0 & 0 & 0 & 1 & 0 & 0 & 0 & 1\end{array}$ $\begin{array}{llllllllllllllllllllllllllllll}\text { Passeri- } & 2 & 1 & 0 & 0 & 0 & 1 & 2 & 1 & 1 & 0 & 0 & 0 & 0 & 0 & 0 & 0 & 0 & 0 & 0 & 0 & 0 & 1 & 0 & 0 & 0 & 1\end{array}$ formes

$\begin{array}{llllllllllllllllllllllllllll}\text { Pici } & 0 & 0 & 0 & 01 & 0 & 1 & 0 & 01 & 1 & 0 & 0 & 0 & 0 & 0 & 3 & 0 & 0 & 0 & 0 & 0 & 0 & 1 & 1 & 0 & 0 & 1\end{array}$ $\begin{array}{lllllllllllllllllllllllllllll}\text { Galbulae } & 0 & 0 & 1 & 1 & 0 & 1 & 0 & 0 & 1 & 0 & 0 & 0 & 0 & 0 & 3 & 0 & 0 & 0 & 0 & 0 & 0 & 1 & 1 & 0 & 0 & 1\end{array}$ $\begin{array}{llllllllllllllllllllllllllll}\text { Trogonidae } & 0 & 0 & 1 & 0 & 0 & 2 & 02 & 0 & 1 & 0 & 0 & 0 & 0 & 0 & 0 & 0 & 1 & 0 & 0 & 0 & \mathbf{0} & 1 & 0 & 0 & 0 & 1\end{array}$ 


\begin{tabular}{|c|c|c|c|c|c|c|c|c|c|c|c|c|c|c|c|c|c|c|c|c|c|c|c|c|c|c|}
\hline \multirow[t]{2}{*}{ Taxa } & \multicolumn{26}{|c|}{ Characters and character states } \\
\hline & 52 & 53 & 54 & 55 & 56 & 57 & 58 & 59 & 60 & 61 & 62 & 63 & 64 & 65 & 66 & 67 & 68 & 69 & 70 & 71 & 72 & 73 & 74 & 75 & 76 & 77 \\
\hline $\begin{array}{l}\dagger \text { †ygodac- } \\
\text { tylus }\end{array}$ & 2 & 1 & 0 & 0 & $?$ & 1 & 2 & 0 & 1 & 0 & 2 & 0 & 0 & 0 & 3 & 0 & $?$ & 0 & 0 & 0 & $\mathbf{0}$ & $?$ & $?$ & $?$ & $?$ & $?$ \\
\hline $\begin{array}{l}\dagger \text { Primozygo- } \\
\text { dactylus }\end{array}$ & 2 & 1 & 0 & 0 & 0 & 1 & 2 & 0 & 1 & 0 & 2 & 0 & 0 & 0 & 3 & 0 & $?$ & 0 & 0 & 0 & $\mathbf{0}$ & $?$ & $?$ & $?$ & $?$ & $?$ \\
\hline$\dagger$ Pumiliornis & 0 & 0 & 0 & 0 & $?$ & $?$ & $?$ & 0 & $?$ & 0 & $?$ & 0 & 0 & $?$ & 23 & 0 & $?$ & 0 & 0 & 0 & $\mathbf{0}$ & $?$ & $?$ & $?$ & $?$ & $?$ \\
\hline$\dagger$ Psittacopes & 0 & 0 & 0 & 0 & 0 & 1 & 1 & 0 & $?$ & 0 & 0 & 1 & 0 & 1 & 3 & 0 & $?$ & 0 & 0 & 0 & $\mathbf{0}$ & $?$ & $?$ & $?$ & $?$ & $?$ \\
\hline$\dagger$ Vastanavis & 1 & 0 & 0 & 0 & 1 & 1 & 1 & 0 & 0 & 0 & 1 & 0 & 0 & 0 & 1 & $?$ & $?$ & $?$ & $?$ & 01 & $?$ & $?$ & $?$ & $?$ & $?$ & $?$ \\
\hline $\begin{array}{l}\text { †Quercy- } \\
\text { psitta }\end{array}$ & 0 & 0 & 0 & 0 & 1 & 1 & 2 & 0 & 1 & 0 & 1 & 1 & 1 & 1 & 3 & $?$ & $?$ & $?$ & $?$ & $?$ & $?$ & $?$ & $?$ & $?$ & $?$ & $?$ \\
\hline $\begin{array}{l}\dagger \text { Pseudastu- } \\
\quad \text { rides }\end{array}$ & 0 & 0 & 1 & 0 & 1 & 0 & 0 & 0 & 1 & 0 & 0 & 1 & 0 & 1 & 2 & 0 & $?$ & 0 & 1 & 0 & $\mathbf{0}$ & $?$ & $?$ & $?$ & $?$ & $?$ \\
\hline$\dagger$ Cyrilavis & 0 & 0 & 1 & 0 & $?$ & 0 & 0 & 0 & 1 & 0 & 0 & 1 & 0 & $?$ & 2 & 0 & $?$ & 0 & 1 & 0 & $\mathbf{0}$ & $?$ & $?$ & $?$ & $?$ & $?$ \\
\hline$\dagger$ Serudaptus & 1 & 0 & $?$ & 0 & $?$ & $?$ & $?$ & $?$ & $?$ & 0 & 0 & $?$ & 0 & $?$ & 2 & 0 & $?$ & 1 & 1 & 1 & $\mathbf{0}$ & $?$ & $?$ & $?$ & $?$ & $?$ \\
\hline$\dagger$ Avolatavis & 1 & 0 & 0 & 0 & 1 & $?$ & 1 & $?$ & $?$ & 0 & 1 & 0 & 0 & $?$ & 1 & 0 & $?$ & 1 & 1 & 1 & $\mathbf{0}$ & $?$ & $?$ & $?$ & $?$ & $?$ \\
\hline $\begin{array}{l}\dagger \text { Eurofluvio- } \\
\text { viridavis }\end{array}$ & 1 & 0 & 0 & 0 & $?$ & $?$ & 12 & $?$ & $?$ & 0 & 1 & $?$ & 0 & $?$ & 1 & 0 & $?$ & 1 & 1 & 1 & $?$ & $?$ & $?$ & $?$ & $?$ & $?$ \\
\hline $\begin{array}{l}\text { †Sandcolei- } \\
\text { dae }\end{array}$ & 0 & 0 & 0 & 0 & 0 & 1 & 1 & 0 & 0 & 0 & 0 & 0 & 0 & 0 & 1 & 0 & $?$ & 1 & 1 & 0 & $\mathbf{0}$ & $?$ & $?$ & $?$ & $?$ & $?$ \\
\hline$†$ Messelastur & 0 & 0 & 1 & 0 & $?$ & 0 & 0 & 0 & $?$ & 0 & 0 & $?$ & 0 & $?$ & 1 & 0 & $?$ & 1 & 1 & 1 & 1 & $?$ & $?$ & $?$ & $?$ & $?$ \\
\hline$\dagger$ Tynskya & $\mathbf{0}$ & $\mathbf{0}$ & 1 & $\mathbf{0}$ & 1 & $\mathbf{0}$ & $\mathbf{0}$ & $\mathbf{0}$ & $?$ & $\mathbf{0}$ & $\mathbf{0}$ & 1 & $\mathbf{0}$ & 1 & 1 & $?$ & $?$ & 1 & 1 & 1 & $?$ & $?$ & $?$ & $?$ & $?$ & $?$ \\
\hline$\dagger$ Morsoravis & 0 & $?$ & $?$ & $?$ & 0 & $?$ & $?$ & 0 & $?$ & 0 & 0 & 0 & 0 & $?$ & $?$ & $?$ & $?$ & 0 & 0 & 0 & $\mathbf{0}$ & $?$ & $?$ & $?$ & $?$ & $?$ \\
\hline$\dagger$ Eocuculus & 0 & 0 & 0 & 0 & 0 & $?$ & $?$ & 0 & ? & 0 & 0 & 0 & 0 & 0 & $?$ & 0 & $?$ & 0 & 0 & 0 & $\mathbf{0}$ & $?$ & $?$ & $?$ & $?$ & $?$ \\
\hline
\end{tabular}

Acknowledgements I am indebted to Jason Bergdahl for facilitating the acquisition of the collection of his father, the late Paul Bergdahl. Sven Tränkner (SMF) is acknowledged for taking the photographs. Gertrud Rößner (SNSB-BSPG) enabled access to the holotype of Tynskya eocaena. Michael Daniels is thanked for access to his private collection of London Clay birds during earlier visits. Comments from the reviewers, Albert Chen and Federico Degrange, improved the manuscript.

Funding Open Access funding enabled and organized by Projekt DEAL.

Open Access This article is licensed under a Creative Commons Attribution 4.0 International License, which permits use, sharing, adaptation, distribution and reproduction in any medium or format, as long as you give appropriate credit to the original author(s) and the source, provide a link to the Creative Commons licence, and indicate if changes were made. The images or other third party material in this article are included in the article's Creative Commons licence, unless indicated otherwise in a credit line to the material. If material is not included in the article's Creative Commons licence and your intended use is not permitted by statutory regulation or exceeds the permitted use, you will need to obtain permission directly from the copyright holder. To view a copy of this licence, visit http://creativecommons.org/licenses/by/4.0/.

\section{References}

Aldiss, D.T. 2012. The stratigraphical framework for the Palaeogene successions of the London Basin, UK. British Geological Survey Open Report OR/12/004: 1-87.
Collinson, M.E., N.F. Adams, S.R. Manchester, G.W. Stull, F. Herrera, S.Y. Smith, M.J. Andrew, P. Kenrick, and D. Sykes. 2016. X-ray micro-computed tomography (micro-CT) of pyrite-permineralized fruits and seeds from the London Clay Formation (Ypresian) conserved in silicone oil: a critical evaluation. Botany 94: 697-711.

Elzanowski, A., G.S. Paul, and T.A. Stidham. 2001. An avian quadrate from the Late Cretaceous Lance Formation of Wyoming. Journal of Vertebrate Paleontology 20: 712-719.

Ericson, P.G.P., C.L. Anderson, T. Britton, A. Elzanowski, U.S. Johansson, M. Källersjö, J.I. Ohlson, T.J. Parsons, D. Zuccon, and G. Mayr. 2006. Diversification of Neoaves: integration of molecular sequence data and fossils. Biology Letters 2: 543-547.

Fowler, D.W., E.A. Freedman Fowler, and J.M. Alexander. 2018. The finest fossil owl. Journal of Vertebrate Paleontology, Program and Abstracts 2018: 129.

Goloboff, P.A. 1993. NONA version 2.0 [Computer software]. S. M. de Tucumán: published by the author.

Grande, L. 2013. The lost world of Fossil Lake. Snapshots from deep time. Chicago: University of Chicago Press.

Hackett, S.J., R.T. Kimball, S. Reddy, R.C.K. Bowie, E.L. Braun, M.J. Braun, J.L. Chojnowski, W.A. Cox, K.-L. Han, J. Harshman, C.J. Huddleston, B.D. Marks, K.J. Miglia, W.S. Moore, F.H. Sheldon, D.W. Steadman, C.C. Witt, and T. Yuri. 2008. A phylogenomic study of birds reveals their evolutionary history. Science 320: 1763-1767.

Hoch, E. 1988. On the ecological role of an Eocene bird from Messel, West Germany. Courier Forschungsinstitut Senckenberg 107: 249-261.

Jarvis, E.D., S. Mirarab, A.J. Aberer, B. Li, P. Houde, C. Li, S.Y.W. Ho, B.C. Faircloth, B. Nabholz, J.T. Howard, A. Suh, C.C. Weber, R.R. da Fonseca, J. Li, F. Zhang, H. Li, L. Zhou, N. Narula, L. Liu, G. Ganapathy, B. Boussau, M.S. Bayzid, V. Zavidovych, S. Subramanian, T. Gabaldón, S. Capella-Gutiérrez, J. Huerta-Cepas, B. Rekepalli, K. Munch, M. Schierup, (75 further co-authors), 
et al. 2014. Whole-genome analyses resolve early branches in the tree of life of modern birds. Science 346: 1320-1331.

Jolley, D.W. 1996. The earliest Eocene sediments of eastern England: an ultra-high resolution palynological correlation. Geological Society, London, Special Publications 101: 219-254.

Ksepka, D.T., and J.A. Clarke. 2012. A new stem parrot from the Green River Formation and the complex evolution of the grasping foot in Pan-Psittaciformes. Journal of Vertebrate Paleontology 32: 395-406.

Ksepka, D.T., J.A. Clarke, and L. Grande. 2011. Stem parrots (Aves, Halcyornithidae) from the Green River Formation and a combined phylogeny of Pan-Psittaciformes. Journal of Paleontology 85: 835-852.

Ksepka, D.T., L. Grande, and G. Mayr. 2019. Oldest finch-beaked birds reveal parallel ecological radiations in the earliest evolution of passerines. Current Biology 29: 657-663.

Kuhl, H., C. Frankl-Vilches, A. Bakker, G. Mayr, G. Nikolaus, S.T. Boerno, S. Klages, B. Timmermann, and M. Gahr. 2021. An unbiased molecular approach using 3'UTRs resolves the avian familylevel tree of life. Molecular Biology and Evolution 38: 108-127.

Mayr, G. 1998. A new family of Eocene zygodactyl birds. Senckenbergiana Lethaea 78: 199-209.

Mayr, G. 2000. A new raptor-like bird from the Lower Eocene of North America and Europe. Senckenbergiana Lethaea 80: 59-65.

Mayr, G. 2002. On the osteology and phylogenetic affinities of the Pseudasturidae-lower Eocene stem-group representatives of parrots (Aves, Psittaciformes). Zoological Journal of the Linnean Society 136: 715-729.

Mayr, G. 2005. The postcranial osteology and phylogenetic position of the Middle Eocene Messelastur gratulator Peters, 1994-a morphological link between owls (Strigiformes) and falconiform birds? Journal of Vertebrate Paleontology 25: 635-645.

Mayr, G. 2007. New specimens of Eocene stem-group psittaciform birds may shed light on the affinities of the first named fossil bird, Halcyornis toliapicus Koenig, 1825. Neues Jahrbuch für Geologie und Paläontologie, Abhandlungen 244: 207-213.

Mayr, G. 2009. Paleogene fossil birds. Heidelberg: Springer.

Mayr, G. 2011. Well-preserved new skeleton of the Middle Eocene Messelastur substantiates sister group relationship between Messelasturidae and Halcyornithidae (Aves, ?Pan-Psittaciformes). Journal of Systematic Palaeontology 9: 159-171.
Mayr, G. 2015. A reassessment of Eocene parrotlike fossils indicates a previously undetected radiation of zygodactyl stem group representatives of passerines (Passeriformes). Zoologica Scripta 44: 587-602.

Mayr, G. 2017. Avian evolution: the fossil record of birds and its paleobiological significance. Chichester: Wiley-Blackwell.

Mayr, G. 2020. An updated review of the middle Eocene avifauna from the Geiseltal (Germany), with comments on the unusual taphonomy of some bird remains. Geobios 62: 45-59.

Mayr, G., and J. Clarke. 2003. The deep divergences of neornithine birds: a phylogenetic analysis of morphological characters. $\mathrm{Cla}$ distics 19: 527-553.

Mayr, G., and M. Daniels. 1998. Eocene parrots from Messel (Hessen, Germany) and the London Clay of Walton-on-the-Naze (Essex, England). Senckenbergiana Lethaea 78: 157-177.

Mayr, G., and R.P. Scofield. 2014. First diagnosable non-sphenisciform bird from the early Paleocene of New Zealand. Journal of the Royal Society of New Zealand 44: 48-56.

Mayr, G., R.S. Rana, K.D. Rose, A. Sahni, K. Kumar, and T. Smith. 2013. New specimens of the early Eocene bird Vastanavis and the interrelationships of stem group Psittaciformes. Paleontological Journal 47: 1308-1314.

Mayr, G., P.D. Gingerich, and T. Smith. 2020. Skeleton of a new owl from the early Eocene of North America (Aves, Strigiformes) with an accipitrid-like foot morphology. Journal of Vertebrate Paleontology 40: e1769116.

Mosto, M.C., and C.P. Tambussi. 2014. Qualitative and quantitative analysis of talons of diurnal bird of prey. Anatomia, Histologia, Embryologia 43: 6-15.

Nixon, K.C. 2002. WinClada, version 1.00.08 [Computer software]. Ithaca, NY: published by the author.

Peters, D.S. 1994. Messelastur gratulator n. gen. n. spec., ein Greifvogel aus der Grube Messel (Aves: Accipitridae). Courier Forschungsinstitut Senckenberg 170: 3-9.

Prum, R.O., J.S. Berv, A. Dornburg, D.J. Field, J.P. Townsend, E.M. Lemmon, and A.R. Lemmon. 2015. A comprehensive phylogeny of birds (Aves) using targeted next-generation DNA sequencing. Nature 526: 569-573.

Williams, E.E. 1950. Variation and selection in the cervical central articulations of living turtles. Bulletin of the American Museum of Natural History 94: 505-562. 